\title{
The Effects of Social Labels on the Allocation of Resources to Equivalent Stimuli: Does One Rotten Apple Spoil the Whole Barrel?
}

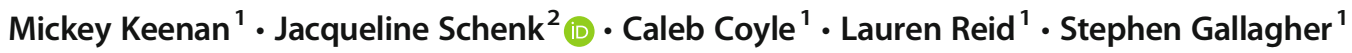 \\ Published online: 10 September 2020 \\ (C) The Author(s) 2020
}

\begin{abstract}
The studies reported here examine how participants distribute resources to arbitrary stimuli in an equivalence class after one stimulus is given a social label. In Experiment 1, two 3-member equivalence classes were established with nonsense syllables (Class 1: A1 (ZID), B1 (YIM), C1 (FAP) and Class 2: A2 (VEK), B2 (RIX), C2 (KUD)) using matching-to-sample training. A social function was then assigned to B1 only, using the simple verbal statement "YIM is a Good person." Next, participants were instructed to allocate tokens to stimuli in whatever way they consider appropriate. In general, the percentage distribution of tokens allocated to Class 1 was greater than those allocated to Class 2. Participants were then informed that a mistake had been made "Sorry I have made a mistake. YIM was actually a bad person not a good person." Participants were again asked to allocate tokens. In general, results showed a reduction in the distribution of tokens allocated to Class 1, with a relatively higher decrease for B1, and an increase in the distribution allocated to Class 2. Experiment 2 replicated Experiment 1 with the addition of a baseline assessment of token distribution prior to examining the effects of adding a social function to B1. During this baseline, the distribution of tokens was relatively similar across both classes. When social functions were added, marked differences occurred in the distribution depending on whether YIM was described as a "Good" or a "Bad" person. Results are discussed regarding transfer of function and its relevance to experimental social psychology.
\end{abstract}

Keywords Stimulus equivalence $\cdot$ Transfer of function $\cdot$ Generalization $\cdot$ Social behavior

The main objective of the experiments reported here was to examine how being a member of a group in which one member is linked to a positive or negative social label ("good" or "bad") has consequences for the allocation of resources. Acquiring such a relatively simple social label might be compared to a person having a certain reputation, something that has consequences for how others behave towards you in terms of social and economic payoffs (e.g., Bolton, Katok, \& Ockenfels, 2004; Cadsby, Servátka, \& Song, 2010; Dale, Morgan, \& Rosenthal, 2002; Schmidt, Shupp, Walker, \& Ostrom, 2003; Servátka, 2010). In

Jacqueline Schenk schenk@essb.eur.nl

Ulster University, Coleraine BT52 1SA, Northern Ireland

2 Erasmus School of Social and Behavioural Sciences, Erasmus University Rotterdam, Mandeville T13-6, Rotterdam 3000 DR, The Netherlands the study by Servátka, for example, the dictator game approach was used in which the "dictator" can give money to the player with whom they are paired (the recipient; see also Guala \& Mittone, 2010; Rousu \& Baublitz, 2011; Tammi, 2013). The experiment consisted of two conditions, one in which participants were paired with a person who had a particular reputation, and another in which participants were paired with a stranger. It was found that, on average, dictators allocated more money to recipients who had a reputation for being generous than to recipients with no reputation (strangers), a result that clearly stresses the effects that a person's reputation may have on how others behave towards you, treat you, or, in this case, reward you.

In recent years, research in the area of stimulus equivalence has provided experimental protocols for establishing relations between arbitrary stimuli such that a group of related stimuli emerges. A standard procedure used is "matching-to-sample" (MTS). For example, a "sample" stimulus (e.g., YIM; coded as A1 by the experimenter) might be presented at the top of a 
computer screen and the participant has to select between two "comparison" stimuli placed underneath (e.g., VEK (coded as B1) and FAP (coded as B2)). Counterbalanced across trials is another arrangement using the same comparison stimuli but a different sample stimulus (e.g., GIX (coded as A2)). The computer is programmed to reinforce a participant's response of selecting A1-B1 and A2-B2 relations. Following mastery of this training, two other sets of relations are trained (e.g., B1-C1 and B2-C2) in the same way. One measure of the relatedness of these stimuli is to use a procedure that tests for $\mathrm{C} 1-\mathrm{A} 1$ relations and C2-A2 relations using the matching-to-sample procedure. Called an "equivalence" test, it shows that in general (but not always), and in some contexts, participants treat these stimuli as equivalent, even though these stimuli were never directly paired during training. Thus, at the end of training the result is that two sets of stimulus classes emerge, $\mathrm{A} 1 \mathrm{~B} 1 \mathrm{C} 1$ and $\mathrm{A} 2 \mathrm{~B} 2 \mathrm{C} 2$. These stimulus classes are called "equivalence classes" because the stimuli can be shown to be substitutable or equivalent for each other.

The procedures used for generating equivalence classes have been shown to be relevant to social psychological research in the areas of social attitudes, social categorization and stereotyping (Leslie et al., 1993; McGlinchey, Keenan, \& Dillenburger, 2000; Moxon, Keenan, \& Hine, 1993). Social attitudes are the evaluations that people make about socially significant objects, events, symbols, groups of people, or individuals, usually in either a positive or negative way (Hewstone, Stroebe, \& Jonas, 2012). The concept of an attitude is a hypothetical construct and the three-component model of attitude structure typically comprises an emotional, cognitive, and behavioral component (Hogg \& Vaughan, 2005) and can involve either explicit (conscious) or implicit (unconscious) associations that are said to influence decisions and behavior. The development of measuring systems for addressing and investigating these issues is the mainstay of much social psychological research (Ajzen \& Fishbein, 2005; Kruglanski \& Stroebe, 2012). The recent interest in relational responding in the field of behavior analysis has sparked the development of techniques for measuring implicit associations (Grey \& Barnes, 1996; Hughes, Barnes-Holmes, \& De Houwer, 2011; O’Reilly, Roche, Ruiz, Tyndall, \& Gavin, 2012; Roche, Barnes-Holmes, Barnes-Holmes, Stewart, \& O’Hora, 2002; Schauss, Chase, \& Hawkins, 1997).

Common to all these techniques is the focus on generating networks of relations between stimuli, often arbitrary, instead of retrospectively speculating about the preceding development of networks of certain stimuli in an individual's social history. One of the first studies to adopt this approach was an experiment by Watt, Keenan, Barnes, and Cairns (1991). The goal of this study was to generate relations between stimuli as a basis for examining how previous social learning might interfere with what might have been expected if socially relevant stimuli had not been used. Using a simple MTS procedure, relations were established first between Catholic names and nonsense syllables (A-B relations) and then between the same nonsense syllables and Protestant symbols (B-C relations). Because the experiment involved participants from Northern Ireland who had a strong tendency to categorize people and events as either Catholic or Protestant (Cairns, 1984), it was thought that it might be possible to disrupt the responding to $\mathrm{C}-\mathrm{A}$ relations that would ordinarily appear in such an experiment when socially neutral stimuli are used. This expectation was confirmed and was bolstered by the finding that English participants who were unfamiliar with the ProtestantCatholic stimuli responded to the $\mathrm{C}-\mathrm{A}$ relations as would normally be expected from participants who lack such social learning history. Variations of this simple experimental paradigm have produced similar results in a wide variety of contexts (Barnes, Lawlor, Smeets, \& Roche, 1996; Dixon, Rehfeldt, Zlomke, \& Robinson, 2006; Merwin \& Wilson, 2005; O'Reilly et al., 2012; Plaud, 1995; Roche \& Barnes, 1996; Roche, O’Reilly, Gavin, Ruiz, \& Arancibia, 2012; Roche, Ruiz, O’Riordan, \& Hand, 2005).

The study of equivalence responding has been extended by additional procedures wherein a specific function/behavior is trained at one of the stimuli in an equivalence class. Once one stimulus in a class has acquired discriminative properties for a behavior, it likely that all stimuli in that class acquire similar properties and the class is called a "functional equivalence class." This phenomenon is called transfer (or transformation; see Dymond \& Rehfeldt, 2000) of function. Tonneau (2001) argued that the theoretical strength of equivalence-based analysis for complex human behavior hinges on transfer of function (see also Greenway, Dougher, \& Wulfert, 1996). A wide range of operant and respondent behaviors, such as transfer of the rate of responding (e.g., Barnes \& Keenan, 1993), transfer of respondent eliciting and extinction functions (e.g., Dougher, Augustson, Markham, Greenway, \& Wulfert, 1994), consequential functions (Hayes, Kohlenberg, \& Hayes, 1991), and motor functions such as clapping and waving (e.g., Barnes, Browne, Smeets, \& Roche, 1995; Bones et al., 2001). Also, transfer of function has been demonstrated using derived relations other than equivalence, such as sameness, opposition, and difference (Dymond \& Barnes, 1996; Whelan \& Barnes-Holmes, 2004), and more than and less than (O'Hora, Roche, Barnes-Holmes, \& Smeets, 2002; Whelan, Barnes-Holmes, \& Dymond, 2006).

The present study extended this line of research in transfer of function by examining it in a social context. We opted for a relatively simple procedure by using a descriptive statement to establish social functions within an equivalence class. McGuigan and Keenan (2002) showed that instructions could be used to generate a transfer of function effect with a simple motor response. The general goal in the current study was to establish an equivalence class, load a social function via a descriptive statement about one of the stimuli, and assess the effects of that function by getting participants to allocate tokens to each member of the stimulus classes. In effect, this procedure is tantamount to a role-play in which one member of a group (i.e., a stimulus class) is given a "reputation" and an 
assessment is made of how the subsequent distribution of available resources is influenced by group membership of a stimulus class.

\section{Experiment 1}

\section{Method}

\section{Participants}

Participants were five students (three males and two females, 21-23 years of age) from Ulster University in Northern Ireland. They were enrolled via opportunity sampling and were given little information initially as to the purpose of the study other than it being a "study of learning." Participants could leave the study at any time.

\section{Materials and Apparatus}

The experiment was conducted in an experimental room in the psychology lab at Ulster University in Northern Ireland. In the room there were two tables, one of which had a chair, and a laptop for training equivalence classes. On the second table, were six stimuli ((i.e., A1 (ZID), B1 (YIM), C1 (FAP), A2 (VEK), B2 (RIX)), and C2 (KUD) printed on flash cards and distributed randomly, face up. A bowl containing 25 tokens was on top of the desk.

\section{General Procedure}

There were seven phases in total during the experiment (Figure 1, top panel) and participants were trained and tested individually. Phases 1, 2, and 3 were used to train and test the two three-member equivalence classes at one table. Phase 4 was used to add a social function to stimulus B1, followed by Phase 5 where token distribution was studied. Finally, Phase 6 was used to reverse the social function and Phase 7 involved a replication of Phase 5.

\section{Phase 1: A-B training}

Using continuous reinforcement in a conditional discrimination procedure, relations were established between stimuli A1-B1 (ZID-YIM) and A2-B2 (VEK-RIX) in blocks of 12 trials. First block of 12 trials involved A1 as a sample stimulus, and after reaching mastery criterion, the next block of 12 trials involved A2 as a sample stimulus. Stimulus A1 was presented at the top of the screen with comparison stimuli B1 and B2 positioned underneath. Across all trials, the positions of the comparison stimuli B1 and B2 were counterbalanced semi-randomly as to eliminate any position bias in responses. In the presence of sample stimulus A1, if the participant chose comparison stimulus B1 then the word "Correct" appeared onscreen. If the participant picked comparison stimulus $\mathrm{B} 2$ in the presence of $\mathrm{A} 1$ then the word "Incorrect" appeared onscreen. If A1-B1 training was less than $92 \%$ accurate (i.e., more than one error in 12 trials), the program repeated the block of 12 trials. If the $92 \%$ criterion was not met after three blocks of trials the experiment was terminated. Once relations between stimuli A1 and B1 had been established to $92 \%$ accuracy, A2-B2 relations were trained. The sample stimulus A2 appeared onscreen with B1 and $\mathrm{B} 2$ as comparison stimuli presented as before; there were 12 trials. This time, selection of B2 produced the word "Correct" whereas selection of B1 produced the word "Incorrect." If A2-B2 training was less than 92\% accurate, the program repeated the block of 12 trials. If the $92 \%$ criterion was not met after three blocks of trials, the experiment was terminated. Once relations between stimuli A2 and B2 had been established to $92 \%$ accuracy, the procedure progressed automatically to Phase 2 .

\section{Phase 2: A-C training}

The conditional discrimination training here was the same as that used in Phase 1, with the same numbers of trials and criteria for progression, only this time the relations trained initially were between A1-C1 (ZID-FAP) and then between A2-C2 (VEK-KUD). Across all trials, the positions of the comparison stimuli $\mathrm{C} 1$ and $\mathrm{C} 2$ were counterbalanced semirandomly in order to eliminate any position bias in responses. As in Phase 1, a criterion of $92 \%$ of correct responses was used to determine when to move from $\mathrm{A} 1-\mathrm{C} 1$ training to $\mathrm{A} 2-$ $\mathrm{C} 2$ training. When the criterion of $92 \%$ correct for $\mathrm{A} 2-\mathrm{C} 2$ responding was met, Phase 3 began automatically.

\section{Phase 3: Testing for B-A, C-A, B-C, and C-B relations}

Phase 3 tested for symmetrical relations (i.e., between $\mathrm{B}-\mathrm{A}$ and $\mathrm{C}-\mathrm{A}$ ) and equivalence relations (i.e., between $\mathrm{B}-\mathrm{C}$ and $\mathrm{C}-\mathrm{B})$. Each of the eight relations (B1-A1, B2-A2, C1-A1, C2-A2, B1-C1, B2-C2, C1-B1, C2-B2) was tested a maximum of 10 times in a random order. Thus $\mathrm{B}-\mathrm{A}$ relations were tested with either B1 or B2 as sample and with $\mathrm{A} 1$ and $\mathrm{A} 2$ as comparisons. There was no feedback during testing of all relations. A criterion of $\geq 90 \%$ correct responses had to be met before participants could move onto the next phase of the experiment. If they did not meet this criterion at the end of the 80 trials in this phase then they could choose to return to Phase 1 or they could finish the experiment.

\section{Phase 4: Addition of Social Function}

In this part of the experiment a social function was added to one of the stimuli, B1. The experimenter simply looked 


\section{Experiment 1}
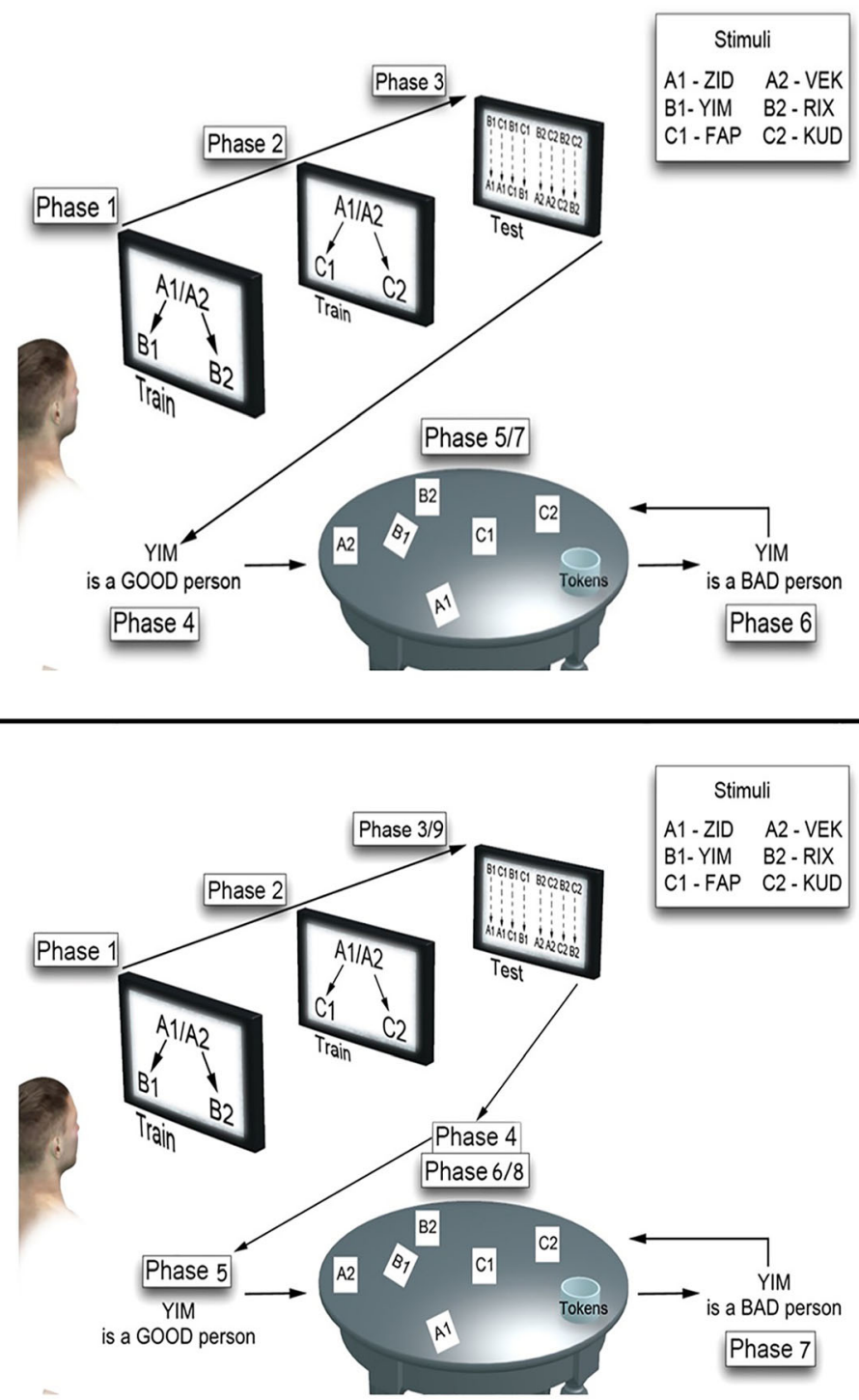

\section{Experiment 2}

Fig. 1 A schematic diagram of the sequence of phases used in each experiment; Experiment 1 top panel, Experiment 2 bottom panel. Solid lines between stimuli in Phases 1-2 indicate directly trained relations whereas dashed lines in Phases 3-9 indicate emergent relations; the desk in the middle of each panel illustrates where and how (face up) stimuli (printed on flash cards) were presented in the presence of a bowl containing tokens (figure made with Smith Micro Software "Poser" and Adobe Photoshop) at the participant and calmly said "YIM is a good person" (GOOD function). This statement was made only once, by the same experimenter on each occasion, and there were no standardized procedures for which clothes the experimenter was to use; this was the case on each occasion in which a social function was added.

\section{Phase 5: Instruction and Distribution of Tokens}

Participants were told that there was a further step in the experiment and brought over to the second table; there was no chair at this table. Participants were read the following instructions: "Here we have six stimuli. I would 
Fig. 2 The total percentage distribution of tokens for each stimulus across all participants in Experiment 1 when YIM was described as "GOOD" and

"BAD"; the bottom value and top value are, respectively, represented in each frame beside each stimulus (figure made with Smith Micro Software "Poser" and Adobe Photoshop)

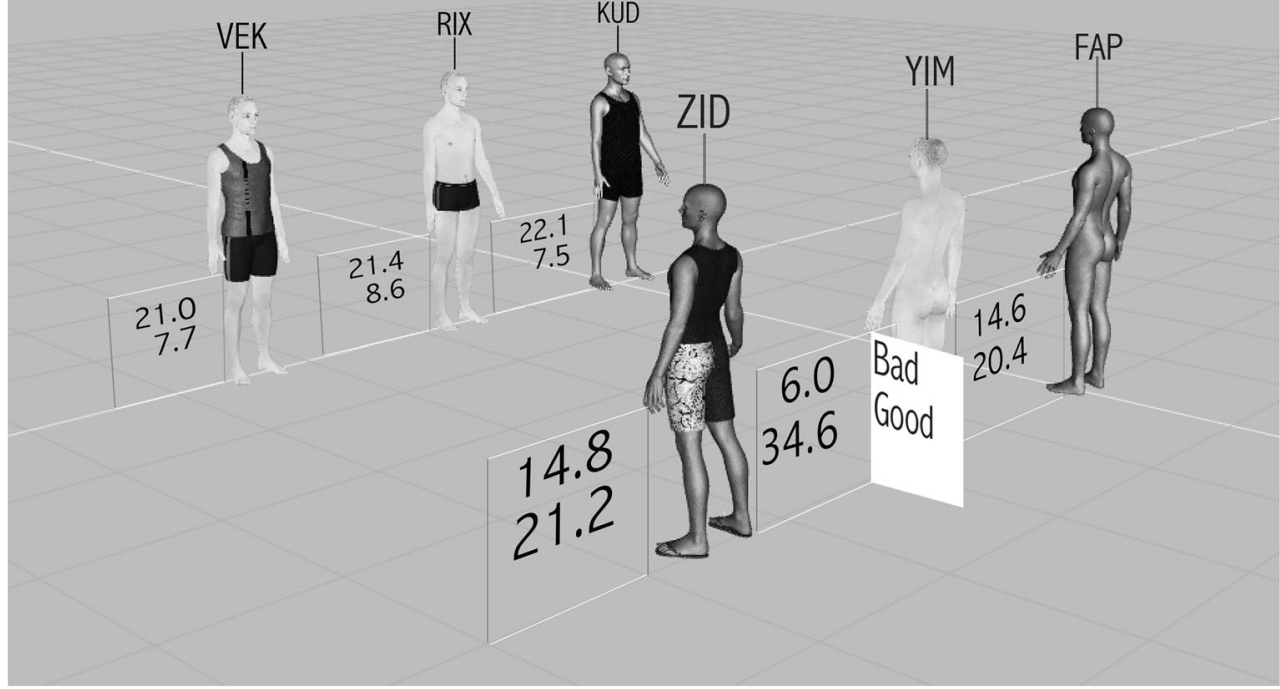

like you to distribute these resources (Experimenter pointed to box containing the tokens) by placing them on top of stimuli of your choosing. I will turn my back to you, so tell me when you are finished." Once the participants told the experimenter that they were finished, the experimenter asked the participant to turn their back to the table and he took a photograph of the results on the table, returned the tokens to the bowl, reorganized the cards on the table in semi-random manner and thanked the participant. Immediately afterwards the same instructions were read to the participant. This process was repeated five times in total for this phase.

\section{Phase 6: Reversal of Social Function}

With their backs to the table used in Phase 5, participants were verbally instructed that a mistake had been made within the experiment (BAD function): "Sorry I have made a mistake. YIM was actually a bad person not a good person."

\section{Phase 7: Distribution of Tokens after Reversal of Social Function}

This phase was an exact replication of Phase 5.

\section{Results}

All participants scored over $90 \%$ on the equivalence test prior to the transfer of function tests and again after the tests were conducted. Figure 2 summarizes the data obtained for all participants across all trials during Phases 5 and 7. When tokens were distributed, not everyone used all the tokens that were available. As a result, the data presented here show the percentage distribution of tokens across all trials and participants that were allocated to each stimulus. At first, Class 1 (ZID, YIM, FAP) received more tokens than Class 2, with YIM receiving the most tokens. Across these participants there was some variation in the extent of this effect with one participant ( $\mathrm{P} 1)$ giving $100 \%$ of the tokens to Class 1 whereas other participants gave $93 \%(\mathrm{P} 3), 61 \%(\mathrm{P} 4)$, and $72 \%(\mathrm{P} 5)$ to this class, respectively. One participant $(\mathrm{P} 3)$ gave substantially more tokens to YIM than to other members of Class 1.

In Phase 6, participants were told that a mistake had been made and that in fact YIM was a "Bad person and not a Good person." The main effect for all five participants was a decrease in the percentage of tokens given to Class 1, whereas Class 2 now received more tokens than it had done in the previous Phase 5. This effect was most pronounced for participant P1 with a change from 0 tokens in Phase 5 to 20 (out of a total of 25) tokens in Phase 7 for Class 2 (i.e., a change from $0 \%$ to $80 \%$ of all tokens distributed between classes). The changes in tokens allocated for Class 2 between Phase 5 and Phase 7 for the other participants were from $49.6 \%$ to $60 \%$ (P2), from $7 \%$ to $61 \%(\mathrm{P} 3)$, from $39 \%$ to $62.5 \%$ (P4), and from $28 \%$ to $58 \%$ (P5). Within Class 1 , there was also a pronounced decrease in relative percentage of tokens given to YIM by all participants. The effect was more pronounced for participant $\mathrm{P} 3$ where YIM received $81 \%$ of Class 1 tokens in Phase 5 but received 0\% in Phase 7. The relative distribution within the class for participant P1 was unchanged but there was a decrease in the total number of tokens allocated. The change in relative distribution within Class 1 for YIM by other participants was from $33.3 \%$ to $20 \%$ (P2), from $33.3 \%$ to $22 \%$ (P4), and from $33.3 \%$ to $21 \%$ (P5). Across participants there was a decrease in the number of tokens given to $\mathrm{B} 1$ in Phase 7 (B1 is "Bad") compared to Phase 5 (B1 is "Good"; Figure 3). A detailed overview of results of each individual participant can be found in Supplementary Materials (Appendix 1: Tables 1, 2, 3, 4, and 5). 
Fig. 3 The total percentage distribution of tokens for each stimulus across all participants in Experiment 2 when no function (NEUTRAL) was associated with YIM and when it was described as "GOOD" and "BAD"; the bottom value, middle value, and top value are, respectively, presented in each frame beside each stimulus (figure made with Smith Micro Software "Poser" and Adobe Photoshop)

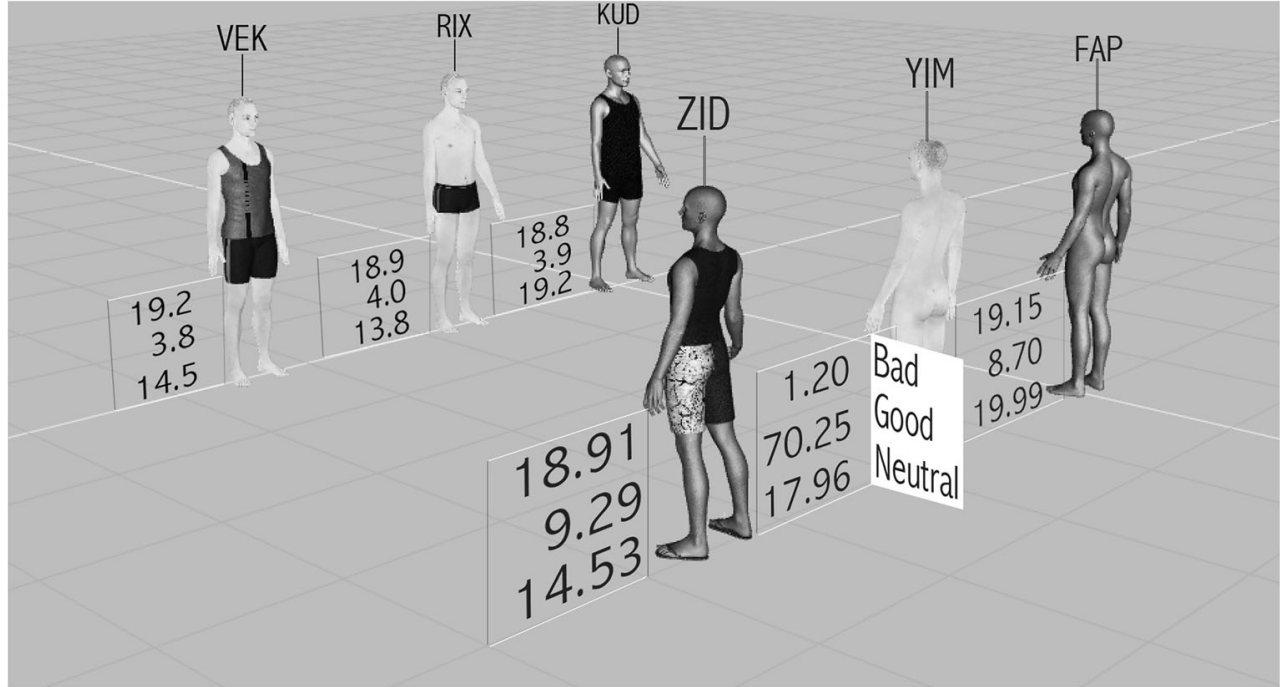

\section{Discussion}

The goal of this experiment was to establish two equivalence classes (A1, B1, C1 and A2, B2, C2) and then examine the effects of manipulating a social function within one class. After all participants had progressed through training and tests for equivalence showed the existence of both classes, a social function was established at B1 (YIM) in Class 1 using a verbal statement (i.e., YIM was described as a "Good person"). Following this instruction, participants were given tokens to distribute to each of the six stimuli from the two classes (Phase 5). There were two general findings. First, for all participants, stimuli in Class 1 received more tokens than stimuli in Class 2, In addition, for one participant, $\mathrm{B} 1$ received more tokens than the other stimuli in Class 1. Also, for all participants, B1 received more tokens than B2 after the original training. The social function was then changed in Phase 6 (i.e., YIM was now described as a "Bad person"). The effect of this was assessed in Phase 7 by again asking participants to distribute tokens. The main finding was that for all participants, the percentage distribution of tokens allocated to Class 1 stimuli decreased and the percentage distribution of tokens allocated to Class 2 stimuli increased. Also, for all participants, B2 received more tokens than B1 following reversal training of the instructions.

Bearing in mind that there were no explicit instructions on how tokens were to be distributed at any time, these findings show that assigning a social value to an arbitrary stimulus in an equivalence is a useful strategy for examining social behavior. The behavior arising from a general instruction to distribute tokens was clearly influenced by the relation between stimuli within the equivalence classes. The distribution of stimuli indicate that social value has function altering effects that are in keeping with findings from transfer/transformation of function studies mentioned earlier.
However, the conclusion is somewhat compromised because there was no assessment of token distribution before a social value was assigned to B1. That is, there is no way of determining whether the initial distribution of tokens arose as a consequence of the social value assigned to $\mathrm{B} 1$ or whether it arose because of a bias in favor of the stimuli chosen for Class 1. The next experiment addressed this shortcoming by getting participants to distribute tokens before a function was added to B1. This would serve as a baseline from which to assess the effects of adding the social function.

\section{Experiment 2}

\section{Method}

\section{Participants}

The participants for this study consisted of eight students (three males and five females, 21-23 years of age) from Ulster University in Northern Ireland. They were enrolled through opportunity sampling through face-to-face interaction. The participants were given little information about the study prior to the experiment other than a participation number and that the experiment is a study of learning. Afterwards they were fully debriefed.

\section{Apparatus and Materials}

The experimental setup was virtually the same as that used in Experiment 1 (Figure 1, bottom panel). The only difference was that due to an experimenter oversight 21 tokens were used instead of 25 . 


\section{Procedure}

Phases 1-3 were exactly the same as those in Experiment 1 (see Figure 1 for an overview of the general procedure).

\section{Phase 4: Distribution of Tokens}

Here participants were asked to distribute tokens using the general procedure in Experiment 1. There was no function added to any stimuli (NEUTRAL function).

\section{Phase 5: Adding a Social Function}

Using the general procedure described in Experiment 1, a social function was assigned to stimulus B1 (YIM) informing the participants that "YIM" is a good person (GOOD function).

\section{Phase 6: Distribution of Tokens}

Using the general procedure described in Experiment 1, participants were instructed to distribute the tokens as they considered appropriate.

\section{Phase 7: Reversal of Social Function}

Using the general procedure described in Experiment 1, participants were informed that there had been a mistake made and that YIM is actually a bad person and not a good person (BAD function).

\section{Phase 8: Distribution of Tokens after Reversal of Social Function}

This phase was an exact replication of Phase 6 .

\section{Phase 9: Equivalence Testing}

The final phase was an exact replication of Phase 3 except there was no criterion performance required. They were then tested without training for $\mathrm{B}-\mathrm{A}, \mathrm{B}-\mathrm{C}, \mathrm{C}-\mathrm{A}$, and $\mathrm{C}-\mathrm{B}$ relations within Class 1 (A1-ZID, B1-YIM, C1-FAP) and Class 2 (A2-VEK, B2-RIX, C2-KUD). This Phase was used to ensure that the equivalence classes were still in place.

\section{Results}

In Experiment 2, all participants scored over $90 \%$ on the equivalence test prior to the transfer of function tests and again after the tests were conducted (Phase 9). Figure 3 summarizes the data obtained for all participants across all trials during Phases 4, 6, and 8. When tokens were distributed, not everyone used all the tokens that were available. As a result, the data presented here show the percentage distribution of tokens across all trials and participants that were allocated to each stimulus. In Phase 4 (NEUTRAL function), there were no functions trained at any of the stimuli and participants were instructed to distribute the tokens in whatever way they considered appropriate. The general finding was a relatively even distribution of tokens across all stimuli from both classes. During Phase 6 (GOOD function), the distribution changed and Class 1 (ZID, YIM, FAP) now received substantially more tokens than Class 2 (VEK, RIX, KUD). However, within Class 1, the percentage distribution of tokens was skewed towards YIM; some participants (P7, P10, P11, and P12) assigned all of the tokens to YIM. Each of the stimuli in Class 2 received about half of the tokens given to each of A1 (ZID) and C1(FAP). During Phase 8 (BAD function), there was a substantial reduction in the distribution of tokens given to YIM accompanied by an increase in the distribution of tokens for ZID and FAP. The distribution of tokens for Class 2 also matched those for ZID and FAP. A detailed overview of results of each individual participant can be found in Supplementary Materials (Appendix 2: Tables 6, 7, 8, 9, 10, 12, and 13).

\section{General Discussion}

Experiment 1 used an AB design in which the initial performance can be viewed as the baseline condition after which there was a change in the contingencies. There is no doubt that we should have returned to the baseline and used an ABA design. However, at the time, we did not expect that it could be argued by reviewers that such strong preference for YIM would be interpreted as simply a biased preference for a particular nonsense syllable, unrelated to the contingencies that were arranged. In Experiment 2, we provided a different baseline to examine potential biased preference for this nonsense syllable. There was no evidence for any supposed bias for YIM. However, the robustness of the main effect in Experiment 1 was not as strong in Experiment 2. It could be argued that there was little evidence of experimental control. However, the alternative argument is that such findings demonstrate history effects where control is influenced by the effects of prior exposure to the contingencies in the initial condition (see also Hayes, Brownstein, Zettle, Rosenfard, \& Kom, 1986; Keenan, 1999; Watt et al., 1991). That said, there was still 
evidence of how the distribution of resources was influenced by the procedures used to assign "value" to the nonsense syllables.

Across most participants, except for P10, there was no preference any particular stimulus and tokens were evenly distributed across all six stimuli. Once the social function was added to B1 (i.e., by saying YIM is a "Good person") the distribution of tokens changed significantly and there was preferential treatment for Class 1, with B1 often receiving the most tokens. This effect was reversed, however, when the social function was reversed. Of course, there was no function explicitly added to Class 2 and therefore the subsequent change in the distribution to this class raises another question that needs to be investigated. Perhaps the increase in the number of tokens given to Class 2 as well as two members of Class 1 (A1 and C1) is a simple demonstration of the behavioral contrast effect. Behavioral contrast refers to the finding that there is a change in the strength of one response when the rate of reward of a second response is changed or when a change in reinforcement in one context causes behavior to change in the opposite direction in another context (Catania, 1992; Killeen, 2014). Because social labels "Good" and "Bad" may be considered actual social opposites, these labels may well be suitable for demonstrating the behavioral contrast effect, similar to "Catholic" versus "Protestant" in the study by Watt et al. (1991). Also, procedural characteristics that enabled participants' acquisition of trained relations (i.e., the use of "correct" and "incorrect" after comparison selection) may have contributed to the behavioral contrast effect; after all, A1, B1, and $\mathrm{C} 1$ are distinctly different (nonequivalent) from $\mathrm{A} 2$, $\mathrm{B} 2$, and $\mathrm{C} 2$.

Both experiments of the current study add to the literature on transfer of function in equivalence classes. There is clear evidence of experimental control when we examine performance across participants, and some striking examples within participants. But there is nothing exceptional about this range of findings for it is well known that in transfer/transformation of function studies, the effects are not always an inevitable outcome for each participant (see McVeigh \& Keenan, 2009).

It has been standard practice in the literature on transfer/transformation of function to train a function to one stimulus and examine the effects across stimuli. We followed this tradition and extended the way in which a function was trained using a rule-based procedure. We then examined the effect of this rule-based intervention by monitoring the distribution of resources given to each stimulus. We did not simply train the function of giving $\mathrm{X}$ amount of resources directly to
YIM to see what happens. This would have been asking completely different questions to the rule-based intervention we used. Of course, a rule about one nonsense syllable might have an effect on all nonsense syllables for verbally competent participants. The question is, though, once those nonsense syllables are segregated into different classes, how might you examine the effects of the rule? Our decision was to examine the allocation of resources. Any procedure that examines the consequences of using a rule for establishing a function for one particular stimulus will inescapably be construed as an assessment of the indirect effects of that rule.

Unlike prior studies in transfer of function, though, there were no explicit instructions on how to behave and instead a simple verbal description was used to attach an attribution to one member of a class (cf. McGuigan \& Keenan, 2002). It might be argued, though, that the phrase used when reversing the social function (i.e., "YIM was actually a bad person not a good person") acted as an instruction and the results could have been different if the phrase had been just "YIM was actually a bad person." In other words, including "not a good person" is like a double directive to change their initial responses or allocation. There are two responses to this argument. First, when the social function was added initially (Phase 4, Experiment 2), there was no double directive ("YIM was actually a good person not a nonsense syllable") used to change their initial responses for the distribution of tokens to be affected by a phrase that referenced the stimulus. Second, the phrase used was in keeping with the colloquial use of English in Northern Ireland. Of course, this still leaves open the possibility of instructional effects arising from the use of phrases in this context. But this is not a problem because in many respects this is precisely what the study is about. It shows that the function of stimuli in a class can be influenced by social interactions that reference stimuli in a class. The findings also add to the body of research examining attitudes in the context of procedures used to establish complex conditional discriminations between stimuli (e.g., Watt et al., 1991; McGlinchey \& Keenan, 1997).

The results that have been reported here are relevant to social psychology areas of research such as stereotyping and social categorization (Ellemers, Kortekaas, \& Ouwerkerk, 1999; Giles, Reed, \& Harwood, 2010; Hogg \& Vaughan, 2010). The preferential treatment of Class 1 compared to Class 2 regarding the distribution of tokens when B1 was described as a "Good person" could be viewed as being analogous to social discrimination or prejudice. This analogy was further evident when B1 was subsequently described as a 
"Bad person." A basic definition of prejudice is an unjustified attitude toward an individual based solely on that individual's membership within a social group. In Experiment 1, all members of Class 1 received fewer tokens even though B1 was "the only bad apple," so to speak. In Experiment 2, this finding was not replicated and instead other members of the class (A1 and $\mathrm{C} 1$ ) now received more tokens than $\mathrm{B} 1$. The initial inclusion of a neutral function in Experiment 2 might account for this disparity in so far as both $\mathrm{A} 1$ and $\mathrm{C} 1$ recovered tokens to a level previously obtained.

Using the allocation of tokens to describe and study transfer of function, may have both advantages as well as disadvantages; on the one hand, it may not be a sufficiently precise measure because allocating a particular number of tokens to any stimulus on test probes could be affected by other effects than just the actual transfer of functions (such as an individual's preexperimental learning history). Also, when the number of tokens that participants allocated to stimuli on test probes are the same, interpretation in terms of function transfer may be difficult. On the other hand, in theory, using the allocation of tokens to study transfer of function does allow for the objective ranking of stimuli in terms of the number of tokens that participants allocated. This is considered an advantage, because functions that were used in previous studies did not allow for this to happen at all. This advantage, however, will only materialize when enough differences and changes in token allocation are observed in a sufficient number of participants. This will then also enable the use of inferential statistical analyses, which will enable more substantial conclusions regarding possible transfer of functions using social labels. Future experiments could focus on this and other methodological variations not studied here such as (1) history effects across different sequencing of conditions such as stating with "YIM is bad," (2) different training methods for establishing equivalence classes, (3) different reversal instructions, and (4) different social labels. Regarding the first suggestion, future studies could focus on the effects of variations in sequencing "GOOD," "BAD" conditions on subsequent token allocation.

Regarding the second suggestion, in the current experiments, blocks of 12 training trials were used to establish $\mathrm{A}-\mathrm{B}$ and $\mathrm{A}-\mathrm{C}$ relations; if, however, participants were to receive overtraining of for example $\mathrm{A}-\mathrm{B}$, while receiving training as usual on $\mathrm{A}-\mathrm{C}$, this may positively influence the strength between $\mathrm{A} 1-\mathrm{B} 1$ and $\mathrm{A} 2-\mathrm{B} 2$ and affect transfer of functions in two ways; first, increased relational strength may produce increased transfer of function (i.e., A1 receiving more resources than $\mathrm{C} 1$ ) and, second, it may lead to less resistance to reversal (i.e., A1 receiving less resources after B1 is labelled negatively, than $\mathrm{C} 1$ ). The latter may be the experimental operationalization of social psychological concepts such as "loyalty" and "in group identification" (Gaertner, Dovidio, Anastasio, Bachman, \& Rust, 1993). The effects of overtraining on relational strength were recently demonstrated in a study by Bortoloti, Rodrigues, Cortez, Pimentel, and de Rose (2013) and offers promising opportunities to explore regarding the current aim to experimentally approach social psychological concepts. Of course, this all speculation on our part and there may be better ways to manipulate the strength of relations within equivalence classes. Also, more attention could be given to issues around contextual control (Bush, Sidman, \& de Rose, 1989; Gatch \& Osborne, 1989; Kohlenberg, Hayes, \& Hayes, 1991; Randell \& Remington, 2006).

Regarding the third suggestion, the instructions used in the current experiments ("YIM is a good/bad person") not only provided social labels but also suggested that originally nonsense words actually represented individuals, which may or may not have an extra effect on resource allocation (before and after reversal). Recent research by Arntzen, Nartey, and Fields (2014) and Fields, Arntzen, Nartey, and Eilifsen (2012) may be relevant here. They examined the effects of meaningful stimuli in the creation of equivalence classes and found that the formation of equivalence classes was enhanced compared to equivalence class formation of arbitrary stimuli only. In the current study, however, equivalence classes already existed before the social functions were added. Thus, adding a social function may be viewed as including a meaningful stimulus (e.g., good/bad) to an existing class and the resulting changes may in turn have contributed in some way to the eventual distribution of resource. Future experiments should also explore the effects of a variety of methods to assign social labels to members of equivalence classes on subsequent resource allocation. One example of this might be to use differential consequences during $\mathrm{A} 1-\mathrm{B} 1, \mathrm{C} 1-\mathrm{B} 1$ training on one hand and $\mathrm{A} 2-\mathrm{B} 2$ and $\mathrm{C} 2-\mathrm{B} 2$ on the other hand, where consequences are already associated with "good" or "bad," such as tokens showing angelic versus devilish emotions. Previous research has demonstrated that class-specific consequences are likely to become a member of their respective equivalence classes (Barros, Lionello-DeNolf, Dube, \& McIlvane, 2006; Dube, McIlvane, Mackay, \& Stoddard, 1987; Dube \& McIlvane, 1995; Lionello-DeNolf, Dube, and Mcllvane, 2006; Pilgrim, 2004; Schenk, 1994) by providing differential socially loaded emoticon tokens as consequences 
during $\mathrm{A}-\mathrm{B}$ and $\mathrm{C}-\mathrm{B}$ training. As a consequence, $\mathrm{A}$ and $\mathrm{C}$ stimuli may acquire social loading by emergent relations with "good" or "bad" emoticons, which may generate different resource allocation effects compared to acquiring social loading by function transfer from B.

Regarding the fourth suggestion, the current experiments were limited to the use of only two social labels (i.e., good and bad). Using a variety of socially opposite labels, such as altruistic versus egoistic or capitalist versus socialist, one could also study effects of reversal, or resistance to reversal, when using social labels that imply more permanent versus more temporary person characteristics.

To conclude, the present study offers another avenue for an experimental study of social behavior. We have not proffered a conceptual framework for interpreting the effects of the procedures used beyond staying within the approach taken in general by the experimental analysis of behavior. When contingencies are arranged in the way described here, then it makes sense for the interpretation of outcomes to be anchored in an analysis of the contingencies that were employed. Future research can vary systematically aspects of what was done here to explore and extend the general findings. The basic approach was to generate relations between arbitrary stimuli such that two different classes emerged and then to examine transfer/transformation of function using a social behavior that involved the distribution of tokens to class members. The advantage of doing this is that it provides control over the kinds of relations that are used to establish group membership. Future studies could examine other kinds of functions that might be added via descriptions (e.g., rulegoverned behavior) and compare the results to behaviors that are directly trained (e.g., contingency-shaped behavior; for discussions of rule-governed and contingencyshaped behavior, see Hayes, 1989). It might also be interesting to use a variety of other procedures to initially establish relational networks (see Barnes-Holmes, Barnes-Holmes, Smeets, Cullinan, \& Leader, 2004) instead of using the simple match-to-sample procedure used here and then determine how the outcomes produced by each procedure map onto assessments conducted by traditional pencil and paper measurements of attitudes.

Other variations in the basic experimental setup could include experiments that explore what happens when a variety of names are used to establish equivalence classes instead of using arbitrary nonsense syllables. For example, studies could use a participant's own name, or examine the effects of using a friend's name compared to the name of a stranger. Likewise, the effects of using an immigrant's name versus nonimmigrant's name could be compared. In a follow-up to the study by Watt et al. (1991), Catholic and Protestant names could be used with Northern Irish participants and this could be compared to results obtained in similar contexts where there is community conflict. Of course, the distribution of tokens is a very limited example of social behavior and there is no way within the current procedure to determine its construct validity with regard to actual social behavior in real life situations; one example might include a case in which one member of a group loses their reputation whereas another example might include changes in behavior after a particular reputation is reestablished. Another suggestion might be to examine if arbitrary stimuli could also be used and worn as badges by real people to see if the interactions demonstrated here extend to real world simulations. Other studies might explore whether the same effects reported here might be replicated if more complex social behaviors were used. To conclude, the current findings tentatively suggest that procedures used in the study of relational responding within equivalence classes could provide opportunities for examining social psychological constructs such as social attitudes (Stahlberg \& Frey, 1988), social categorization, and stereotyping.

Availability of Data and Materials Data supporting our findings can be found in Appendices A and B or can be obtained by contacting the first author.

Funding The authors received no financial support for the research, authorship, and/or publication of this article.

\section{Compliance with Ethical Standards}

Conflict of Interest On behalf of all authors, the corresponding author states that there is no conflict of interest.

Ethical Approval All procedures performed in studies involving human participants were in accordance with the ethical standards of the institutional research committee and with the 1964 Helsinki declaration and its later amendments or comparable ethical standards.

Informed Consent Informed consent was obtained from all individual participants included in the study 


\section{Appendix 1}

Results of Participants 1-5 (Experiment 1)

Table 1. The Distribution of Tokens across Trials for P1

\begin{tabular}{|c|c|c|c|c|c|c|}
\hline Trials & Stimuli & & & & & \\
\hline Phase 5 & A1 & B1 & $\mathrm{C} 1$ & $\mathrm{~A} 2$ & B2 & $\mathrm{C} 2$ \\
\hline YIM Good & ZID & YIM & FAP & VEK & RIX & KUD \\
\hline 1 & 9 & 8 & 8 & 0 & 0 & 0 \\
\hline 2 & 9 & 8 & 8 & 0 & 0 & 0 \\
\hline 3 & 9 & 8 & 8 & 0 & 0 & 0 \\
\hline 4 & 9 & 8 & 8 & 0 & 0 & 0 \\
\hline 5 & 9 & 8 & 8 & 0 & 0 & 0 \\
\hline Average & 9 & 8 & 8 & 0 & 0 & 0 \\
\hline$\%$ Distribution within each class & $36 \%$ & $32 \%$ & $32 \%$ & - & - & - \\
\hline$\%$ Distribution overall & $36 \%$ & $32 \%$ & $32 \%$ & $0 \%$ & $0 \%$ & $0 \%$ \\
\hline Distribution per class & $\begin{array}{l}\mathrm{A} 1, \mathrm{~B} 1, \mathrm{C} 1 \\
\mathrm{~A} 2, \mathrm{~B} 2, \mathrm{C} 2\end{array}$ & $\begin{array}{l}\text { Total of class average } \\
25.0 \\
0.0\end{array}$ & $\begin{array}{l}\% \text { of Total per class } \\
100 \% \\
0 \%\end{array}$ & & & \\
\hline $\begin{array}{l}\text { Phase } 7 \\
\text { YIM Bad }\end{array}$ & & & & & & \\
\hline 1 & 9 & 8 & 8 & 0 & 0 & 0 \\
\hline 2 & 0 & 0 & 0 & 8 & 9 & 8 \\
\hline 3 & 0 & 0 & 0 & 8 & 8 & 9 \\
\hline 4 & 0 & 0 & 0 & 8 & 8 & 9 \\
\hline 5 & 0 & 0 & 0 & 8 & 8 & 9 \\
\hline Average & 1.8 & 1.6 & 1.6 & 6.4 & 6.6 & 7 \\
\hline$\%$ Distribution within each class & $36 \%$ & $32 \%$ & $32 \%$ & $32 \%$ & $33 \%$ & $35 \%$ \\
\hline$\%$ Distribution overall & $7.2 \%$ & $6.4 \%$ & $6.4 \%$ & $25.6 \%$ & $26.4 \%$ & $28 \%$ \\
\hline Distribution per class & $\begin{array}{l}\text { A1,B1,C1 } \\
\text { A2,B2,C2 }\end{array}$ & $\begin{array}{l}\text { Total of class average } \\
5.0 \\
20.0\end{array}$ & $\begin{array}{l}\% \text { of Total per class } \\
20 \% \\
80 \%\end{array}$ & & & \\
\hline
\end{tabular}


Table 2. The Distribution of Tokens across Trials for P2

\begin{tabular}{|c|c|c|c|c|c|c|}
\hline Trials & Stimuli & & & & & \\
\hline Phase 5 & A1 & B1 & $\mathrm{C} 1$ & $\mathrm{~A} 2$ & B2 & $\mathrm{C} 2$ \\
\hline YIM Good & ZID & YIM & FAP & VEK & RIX & KUD \\
\hline 1 & 4 & 5 & 4 & 4 & 4 & 4 \\
\hline 2 & 5 & 4 & 4 & 4 & 4 & 4 \\
\hline 3 & 4 & 4 & 5 & 4 & 4 & 4 \\
\hline 4 & 4 & 4 & 4 & 4 & 5 & 4 \\
\hline 5 & 4 & 4 & 4 & 5 & 4 & 4 \\
\hline Average & 4.2 & 4.2 & 4.2 & 4.2 & 4.2 & 4 \\
\hline$\%$ Distribution within each class & $33.3 \%$ & $33.3 \%$ & $33.3 \%$ & $34 \%$ & $34 \%$ & $32 \%$ \\
\hline$\%$ Distribution overall & $16.8 \%$ & $16.8 \%$ & $16.8 \%$ & $16.8 \%$ & $16.8 \%$ & $16 \%$ \\
\hline \multirow[t]{3}{*}{ Distribution per class } & $\mathrm{A} 1, \mathrm{~B} 1, \mathrm{C} 1$ & Total of class average & $\%$ of Total per class & & & \\
\hline & $\mathrm{A} 2, \mathrm{~B} 2, \mathrm{C} 2$ & 12.6 & $50.4 \%$ & & & \\
\hline & & 12.4 & $49.6 \%$ & & & \\
\hline \multicolumn{7}{|l|}{ Phase 7} \\
\hline \multicolumn{7}{|l|}{ YIM Bad } \\
\hline 1 & 5 & 0 & 5 & 5 & 5 & 5 \\
\hline 2 & 4 & 2 & 4 & 5 & 5 & 5 \\
\hline 3 & 4 & 3 & 4 & 5 & 4 & 5 \\
\hline 4 & 3 & 2 & 3 & 6 & 6 & 5 \\
\hline 5 & 4 & 3 & 4 & 4 & 5 & 5 \\
\hline Average & 4 & 2 & 4 & 5 & 5 & 5 \\
\hline$\%$ Distribution within each class & $40 \%$ & $20 \%$ & $40 \%$ & $33.3 \%$ & $33.3 \%$ & $33.3 \%$ \\
\hline$\%$ Distribution overall & $16 \%$ & $8 \%$ & $16 \%$ & $20 \%$ & $20 \%$ & $20 \%$ \\
\hline \multirow[t]{3}{*}{ Distribution per class } & $\mathrm{A} 1, \mathrm{~B} 1, \mathrm{C} 1$ & Total of class average & $\%$ of Total per class & & & \\
\hline & $\mathrm{A} 2, \mathrm{~B} 2, \mathrm{C} 2$ & 10.0 & $40.0 \%$ & & & \\
\hline & & 15.0 & $60.0 \%$ & & & \\
\hline
\end{tabular}

Table 3. The Distribution of Tokens across Trials for P3

\begin{tabular}{|c|c|c|c|c|c|c|}
\hline Trials & Stimuli & & & & & \\
\hline Phase 5 & $\mathrm{~A} 1$ & B1 & $\mathrm{C} 1$ & $\mathrm{~A} 2$ & B2 & $\mathrm{C} 2$ \\
\hline YIM Good & ZID & YIM & FAP & VEK & RIX & KUD \\
\hline 1 & 1 & 20 & 1 & 1 & 1 & 1 \\
\hline 2 & 8 & 9 & 8 & 0 & 0 & 0 \\
\hline 3 & 0 & 25 & 0 & 0 & 0 & 0 \\
\hline 4 & 1 & 20 & 1 & 1 & 1 & 1 \\
\hline 5 & 1 & 20 & 1 & 1 & 1 & 1 \\
\hline Average & 2.2 & 18.8 & 2.2 & 0.6 & 0.6 & 0.6 \\
\hline$\%$ Distribution within each class & $9.5 \%$ & $81 \%$ & $9.5 \%$ & $33.3 \%$ & $33.3 \%$ & $33.3 \%$ \\
\hline$\%$ Distribution overall & $8.8 \%$ & $75.2 \%$ & $8.8 \%$ & 2.4 & 2.4 & 2.4 \\
\hline Distribution per class & $\begin{array}{l}\text { A1,B1,C1 } \\
\text { A2,B2,C2 }\end{array}$ & $\begin{array}{l}\text { Total of class average } \\
23.2 \\
1.8\end{array}$ & $\begin{array}{l}\% \text { of Total per class } \\
92.8 \% \\
7.2 \%\end{array}$ & & & \\
\hline \multicolumn{7}{|l|}{ Phase 7YIM Bad } \\
\hline 1 & 4 & 0 & 4 & 4 & 6 & 7 \\
\hline 2 & 5 & 0 & 5 & 5 & 5 & 5 \\
\hline 3 & 5 & 0 & 5 & 5 & 5 & 5 \\
\hline 4 & 5 & 0 & 5 & 5 & 5 & 5 \\
\hline 5 & 5 & 0 & 6 & 5 & 4 & 5 \\
\hline Average & 4.8 & 0 & 5 & 4.8 & 5 & 5.4 \\
\hline$\%$ Distribution within each class & $49 \%$ & $0 \%$ & $51 \%$ & $32 \%$ & $33 \%$ & $35 \%$ \\
\hline$\%$ Distribution overall & 19.2 & $0 \%$ & $20 \%$ & $19.2 \%$ & $20 \%$ & $21.6 \%$ \\
\hline Distribution per class & $\begin{array}{l}\text { A1,B1,C1 } \\
\text { A2,B2,C2 }\end{array}$ & $\begin{array}{l}\text { Total of class average } \\
9.8 \\
15.2\end{array}$ & $\begin{array}{l}\% \text { of Total per class } \\
39.2 \% \\
60.8 \%\end{array}$ & & & \\
\hline
\end{tabular}


Table 4. The Distribution of Tokens across Trials for P4

\begin{tabular}{|c|c|c|c|c|c|c|}
\hline Trials & Stimuli & & & & & \\
\hline Phase 5 & A1 & B1 & $\mathrm{C} 1$ & A2 & B2 & $\mathrm{C} 2$ \\
\hline YIM Good & ZID & YIM & FAP & VEK & RIX & KUD \\
\hline 1 & 3 & 3 & 3 & 1 & 1 & 1 \\
\hline 2 & 4 & 4 & 4 & 2 & 2 & 2 \\
\hline 3 & 1 & 1 & 1 & 3 & 3 & 3 \\
\hline 4 & 5 & 5 & 5 & 2 & 2 & 2 \\
\hline 5 & 4 & 4 & 4 & 3 & 3 & 3 \\
\hline Average & 3.4 & 3.4 & 3.4 & 2.2 & 2.2 & 2.2 \\
\hline$\%$ Distribution within each class & $33.3 \%$ & $33.3 \%$ & $33.3 \%$ & $33.3 \%$ & $33.3 \%$ & $33.3 \%$ \\
\hline$\%$ Distribution overall & $20.2 \%$ & $20.2 \%$ & $20.2 \%$ & $13.1 \%$ & $13.1 \%$ & $13.1 \%$ \\
\hline Distribution per class & $\begin{array}{l}\mathrm{A} 1, \mathrm{~B} 1, \mathrm{C} 1 \\
\mathrm{~A} 2, \mathrm{~B} 2, \mathrm{C} 2\end{array}$ & $\begin{array}{l}\text { Total of class average } \\
10.2 \\
6.6\end{array}$ & $\begin{array}{l}\% \text { of Total per class } \\
60.7 \% \\
39.3 \%\end{array}$ & & & \\
\hline $\begin{array}{l}\text { Phase } 7 \\
\text { YIM Bad }\end{array}$ & \multicolumn{5}{|c|}{ Phase 7} & \\
\hline 1 & 3 & 2 & 3 & 1 & 1 & 1 \\
\hline 2 & 0 & 0 & 0 & 2 & 2 & 2 \\
\hline 3 & 2 & 1 & 2 & 3 & 3 & 3 \\
\hline 4 & 1 & 0 & 1 & 2 & 2 & 2 \\
\hline 5 & 1 & 1 & 1 & 2 & 2 & 2 \\
\hline Average & 1.4 & 0.8 & 1.4 & 2 & 2 & 2 \\
\hline$\%$ Distribution within each class & $39 \%$ & $22 \%$ & $39 \%$ & $33.3 \%$ & $33.3 \%$ & $33.3 \%$ \\
\hline$\%$ Distribution overall (out of 9.6 average) & $14.6 \%$ & $8.3 \%$ & $14.6 \%$ & $20.8 \%$ & $20.8 \%$ & $20.8 \%$ \\
\hline Distribution per class & $\begin{array}{l}\mathrm{A} 1, \mathrm{~B} 1, \mathrm{C} 1 \\
\mathrm{~A} 2, \mathrm{~B} 2, \mathrm{C} 2\end{array}$ & $\begin{array}{l}\text { Total of class average } \\
3.6 \\
6.0\end{array}$ & $\begin{array}{l}\% \text { of Total per class } \\
37.5 \% \\
62.5 \%\end{array}$ & & & \\
\hline
\end{tabular}

Table 5. The Distribution of Tokens across Trials for P5

\begin{tabular}{|c|c|c|c|c|c|c|}
\hline Trials & Stimuli & & & & & \\
\hline Phase 5 & A1 & B1 & $\mathrm{C} 1$ & A2 & B2 & $\mathrm{C} 2$ \\
\hline YIM Good & ZID & YIM & FAP & VEK & RIX & KUD \\
\hline 1 & 6 & 6 & 6 & 2 & 3 & 2 \\
\hline 2 & 6 & 6 & 6 & 2 & 3 & 2 \\
\hline 3 & 6 & 6 & 6 & 2 & 3 & 2 \\
\hline 4 & 6 & 6 & 6 & 2 & 3 & 2 \\
\hline 5 & 6 & 6 & 6 & 2 & 3 & 2 \\
\hline Average & 6 & 6 & 6 & 2 & 3 & 2 \\
\hline$\%$ Distribution within each class & $33.3 \%$ & $33.3 \%$ & $33.3 \%$ & $28.5 \%$ & $43 \%$ & $28.5 \%$ \\
\hline$\%$ Distribution overall & $24 \%$ & $24 \%$ & $24 \%$ & $8 \%$ & $12 \%$ & $8 \%$ \\
\hline Distribution per class & $\begin{array}{l}\mathrm{A} 1, \mathrm{~B} 1, \mathrm{C} 1 \\
\mathrm{~A} 2, \mathrm{~B} 2, \mathrm{C} 2\end{array}$ & $\begin{array}{l}\text { Total of class average } \\
18.0 \\
7.0\end{array}$ & $\begin{array}{l}\% \text { of Total per class } \\
72.0 \% \\
28.0 \%\end{array}$ & & & \\
\hline \multicolumn{6}{|l|}{ Phase 7} & \\
\hline 1 & 5 & 3 & 4 & 4 & 4 & 4 \\
\hline 2 & 4 & 2 & 4 & 5 & 5 & 5 \\
\hline 3 & 4 & 2 & 4 & 5 & 5 & 5 \\
\hline 4 & 4 & 2 & 4 & 5 & 5 & 5 \\
\hline 5 & 4 & 2 & 4 & 5 & 5 & 5 \\
\hline Average & 4.2 & 2.2 & 4 & 4.8 & 4.8 & 4.8 \\
\hline$\%$ Distribution within each class & $40 \%$ & $21 \%$ & $39 \%$ & $33.3 \%$ & $33.3 \%$ & $33.3 \%$ \\
\hline Distribution overall (\%) & $16.8 \%$ & $8.8 \%$ & $16 \%$ & $19.2 \%$ & $19.2 \%$ & $19.2 \%$ \\
\hline \multirow[t]{3}{*}{ Distribution per class } & $\mathrm{A} 1, \mathrm{~B} 1, \mathrm{C} 1$ & Total of class average & $\%$ of Total per class & & & \\
\hline & $\mathrm{A} 2, \mathrm{~B} 2, \mathrm{C} 2$ & 10.4 & $42.0 \%$ & & & \\
\hline & & 14.4 & $58.0 \%$ & & & \\
\hline
\end{tabular}




\section{Appendix 2}

Results of Participants 6-13 (Experiment 2)

Table 6. The Distribution of Tokens across Trials for P6

\begin{tabular}{|c|c|c|c|c|c|c|}
\hline Trials & Stimuli & & & & & \\
\hline Phase 4 & A1 & B1 & $\mathrm{C} 1$ & A2 & $\mathrm{B} 2$ & $\mathrm{C} 2$ \\
\hline NO Function & ZID & YIM & FAP & VEK & RIX & KUD \\
\hline 1 & 3 & 4 & 3 & 4 & 3 & 4 \\
\hline 2 & 4 & 4 & 4 & 3 & 3 & 3 \\
\hline 3 & 3 & 3 & 3 & 4 & 4 & 4 \\
\hline 4 & 1 & 3 & 2 & 4 & 6 & 5 \\
\hline 5 & 6 & 5 & 4 & 3 & 2 & 1 \\
\hline Average & 3.4 & 3.8 & 3.2 & 3.6 & 3.6 & 3.4 \\
\hline$\%$ Distribution within each class & $32.7 \%$ & $36.5 \%$ & $30.8 \%$ & $34 \%$ & $34 \%$ & $32.1 \%$ \\
\hline$\%$ Distribution overall & $16.2 \%$ & $18.1 \%$ & $15.2 \%$ & $17.1 \%$ & $17.1 \%$ & $16.2 \%$ \\
\hline Distribution per class & $\begin{array}{l}\text { A1,B1,C1 } \\
\text { A2,B2,C2 }\end{array}$ & $\begin{array}{l}\text { Total of class average } \\
10.4 \\
10.6\end{array}$ & $\begin{array}{l}\% \text { of Total per class } \\
49.5 \% \\
50.5 \%\end{array}$ & & & \\
\hline $\begin{array}{l}\text { Phase } 6 \\
\text { YIM Good }\end{array}$ & & & & & & \\
\hline 1 & 7 & 7 & 7 & 0 & 0 & 0 \\
\hline 2 & 6 & 6 & 6 & 1 & 1 & 1 \\
\hline 3 & 7 & 7 & 7 & 0 & 0 & 0 \\
\hline 4 & 7 & 7 & 7 & 0 & 0 & 0 \\
\hline 5 & 6 & 6 & 6 & 1 & 1 & 1 \\
\hline Average & 6.6 & 6.6 & 6.6 & 0.4 & 0.4 & 0.4 \\
\hline$\%$ Distribution within each class & $33.3 \%$ & $33.3 \%$ & $33.3 \%$ & $33.3 \%$ & $33.3 \%$ & $33.3 \%$ \\
\hline$\%$ Distribution overall & $31.4 \%$ & $31.4 \%$ & $31.4 \%$ & $2.0 \%$ & $2.0 \%$ & $2.0 \%$ \\
\hline Distribution per class & $\begin{array}{l}\text { A1,B1,C1 } \\
\text { A2,B2,C2 }\end{array}$ & $\begin{array}{l}\text { Total of class average } \\
19.8 \\
1.2\end{array}$ & $\begin{array}{l}\% \text { of Total per class } \\
94.2 \% \\
5.8 \%\end{array}$ & & & \\
\hline $\begin{array}{l}\text { Phase } 8 \\
\text { YIM Bad }\end{array}$ & & & $\mathrm{s}$ & & & \\
\hline 1 & 0 & 0 & 0 & 7 & 7 & 7 \\
\hline 2 & 2 & 0 & 1 & 6 & 6 & 6 \\
\hline 3 & 2 & 0 & 2 & 5 & 6 & 6 \\
\hline 4 & 3 & 0 & 2 & 5 & 5 & 6 \\
\hline 5 & 3 & 0 & 3 & 5 & 5 & 5 \\
\hline Average & 2 & 0 & 1.6 & 5.6 & 5.8 & 6 \\
\hline$\%$ Distribution within each class & $55.6 \%$ & $0 \%$ & $44.4 \%$ & $32.2 \%$ & $33.3 \%$ & $34.5 \%$ \\
\hline$\%$ Distribution overall & $9.5 \%$ & $0 \%$ & $7.6 \%$ & $26.7 \%$ & $27.6 \%$ & $28.6 \%$ \\
\hline Distribution per class & $\begin{array}{l}\text { A1,B1,C1 } \\
\text { A2,B2,C2 }\end{array}$ & $\begin{array}{l}\text { Total of class average } \\
3.6 \\
17.4\end{array}$ & $\begin{array}{l}\% \text { of Total per class } \\
17.1 \% \\
82.9 \%\end{array}$ & & & \\
\hline
\end{tabular}


Table 7. The Distribution of Tokens across Trials for P7

\begin{tabular}{|c|c|c|c|c|c|c|}
\hline Trials & Stimuli & & & & & \\
\hline Phase 4 & $\mathrm{~A} 1$ & B1 & $\mathrm{C} 1$ & $\mathrm{~A} 2$ & $\mathrm{~B} 2$ & $\mathrm{C} 2$ \\
\hline NO Function & ZID & YIM & FAP & VEK & RIX & KUD \\
\hline 1 & 4 & 3 & 4 & 3 & 3 & 4 \\
\hline 2 & 4 & 4 & 4 & 3 & 3 & 3 \\
\hline 3 & 4 & 4 & 4 & 3 & 3 & 3 \\
\hline 4 & 3 & 4 & 3 & 4 & 3 & 4 \\
\hline 5 & 3 & 4 & 3 & 4 & 4 & 3 \\
\hline Average & 3.6 & 3.8 & 3.6 & 3.4 & 3.2 & 3.4 \\
\hline$\%$ Distribution within each class & $32.7 \%$ & $34.5 \%$ & $32.7 \%$ & $30.9 \%$ & $29.1 \%$ & $30.9 \%$ \\
\hline$\%$ Distribution overall & $17.1 \%$ & $18.1 \%$ & $17.1 \%$ & $16.2 \%$ & $15.2 \%$ & $16.2 \%$ \\
\hline Distribution per class & $\begin{array}{l}\mathrm{A} 1, \mathrm{~B} 1, \mathrm{C} 1 \\
\mathrm{~A} 2, \mathrm{~B} 2, \mathrm{C} 2\end{array}$ & $\begin{array}{l}\text { Total of class average } \\
11 \\
10\end{array}$ & $\begin{array}{l}\% \text { of Total per class } \\
52.3 \% \\
47.7 \%\end{array}$ & & & \\
\hline \multicolumn{7}{|l|}{ Phase 6} \\
\hline 1 & 0 & 21 & 0 & 0 & 0 & 0 \\
\hline 2 & 0 & 21 & 0 & 0 & 0 & 0 \\
\hline 3 & 0 & 21 & 0 & 0 & 0 & 0 \\
\hline 4 & 0 & 21 & 0 & 0 & 0 & 0 \\
\hline 5 & 0 & 21 & 0 & 0 & 0 & 0 \\
\hline Average & 0 & 21 & 0 & 0 & 0 & 0 \\
\hline$\%$ Distribution within each class & $0 \%$ & $100 \%$ & $0 \%$ & $0 \%$ & $0 \%$ & $0 \%$ \\
\hline$\%$ Distribution overall & $0 \%$ & $100 \%$ & $0 \%$ & $0 \%$ & $0 \%$ & $0 \%$ \\
\hline Distribution per class & $\begin{array}{l}\mathrm{A} 1, \mathrm{~B} 1, \mathrm{C} 1 \\
\mathrm{~A} 2, \mathrm{~B} 2, \mathrm{C} 2\end{array}$ & $\begin{array}{l}\text { Total of class average } \\
21 \\
0\end{array}$ & $\begin{array}{l}\% \text { of Total per class } \\
100 \% \\
0 \%\end{array}$ & & & \\
\hline \multicolumn{7}{|l|}{ Phase 8} \\
\hline 1 & 4 & 0 & 4 & 4 & 5 & 4 \\
\hline 2 & 6 & 0 & 6 & 3 & 3 & 3 \\
\hline 3 & 7 & 0 & 7 & 2 & 2 & 3 \\
\hline 4 & 8 & 0 & 8 & 1 & 2 & 2 \\
\hline 5 & 9 & 0 & 9 & 1 & 1 & 1 \\
\hline Average & 6.8 & 0 & 6.8 & 2.2 & 2.6 & 2.6 \\
\hline$\%$ Distribution within each class & $50 \%$ & $0 \%$ & $50 \%$ & $29.7 \%$ & $36.1 \%$ & $36.1 \%$ \\
\hline$\%$ Distribution overall & 32.4 & $0 \%$ & $32.4 \%$ & $10.5 \%$ & $12.4 \%$ & $12.4 \%$ \\
\hline Distribution per class & $\begin{array}{l}\mathrm{A} 1, \mathrm{~B} 1, \mathrm{C} 1 \\
\mathrm{~A} 2, \mathrm{~B} 2, \mathrm{C} 2\end{array}$ & $\begin{array}{l}\text { Total of class average } \\
13.6 \\
7.4\end{array}$ & $\begin{array}{l}\% \text { of Total per class } \\
64.8 \% \\
35.2 \%\end{array}$ & & & \\
\hline
\end{tabular}


Table 8. The Distribution of Tokens across Trials for P8

\begin{tabular}{|c|c|c|c|c|c|c|}
\hline Trials & Stimuli & & & & & \\
\hline Phase 4 & A1 & B1 & $\mathrm{C} 1$ & $\mathrm{~A} 2$ & $\mathrm{~B} 2$ & $\mathrm{C} 2$ \\
\hline NO Function & ZID & YIM & FAP & VEK & RIX & KUD \\
\hline 1 & 6 & 3 & 8 & 0 & 4 & 0 \\
\hline 2 & 4 & 4 & 3 & 3 & 3 & 4 \\
\hline 3 & 4 & 4 & 4 & 3 & 3 & 3 \\
\hline 4 & 4 & 3 & 3 & 3 & 4 & 4 \\
\hline 5 & 4 & 4 & 4 & 3 & 3 & 3 \\
\hline Average & 4.4 & 3.6 & 4.4 & 2.4 & 3.4 & 2.8 \\
\hline$\%$ Distribution within each class & $35.5 \%$ & $29 \%$ & $35.5 \%$ & $27.9 \%$ & $39.5 \%$ & $32.6 \%$ \\
\hline$\%$ Distribution overall & $21 \%$ & $17.1 \%$ & $21 \%$ & $11.4 \%$ & $16.2 \%$ & $13.3 \%$ \\
\hline Distribution per class & $\begin{array}{l}\text { A1,B1,C1 } \\
\text { A2,B2,C2 }\end{array}$ & $\begin{array}{l}\text { Total of class average } \\
12.4 \\
8.6\end{array}$ & $\begin{array}{l}\% \text { of Total per class } \\
59.1 \% \\
40.9 \%\end{array}$ & & & \\
\hline \multicolumn{7}{|l|}{ Phase 6} \\
\hline 1 & 3 & 9 & 2 & 3 & 2 & 2 \\
\hline 2 & 4 & 9 & 1 & 1 & 3 & 3 \\
\hline 3 & 3 & 9 & 2 & 2 & 3 & 2 \\
\hline 4 & 3 & 9 & 3 & 2 & 2 & 2 \\
\hline 5 & 3 & 9 & 3 & 2 & 2 & 2 \\
\hline Average & 3.2 & 9 & 2.2 & 2 & 2.4 & 2.2 \\
\hline$\%$ Distribution within each class & $22.2 \%$ & $62.5 \%$ & $15.3 \%$ & $30.3 \%$ & $36.4 \%$ & $33.3 \%$ \\
\hline$\%$ Distribution overall & $15.2 \%$ & $42.9 \%$ & $10.5 \%$ & $9.5 \%$ & $11.4 \%$ & $10.5 \%$ \\
\hline Distribution per class & $\begin{array}{l}\text { A1,B1,C1 } \\
\text { A2,B2,C2 }\end{array}$ & $\begin{array}{l}\text { Total of class average } \\
14.4 \\
6.6\end{array}$ & $\begin{array}{l}\% \text { of Total per class } \\
68.6 \% \\
31.4 \%\end{array}$ & & & \\
\hline \multicolumn{7}{|l|}{ Phase 8} \\
\hline 1 & 4 & 0 & 4 & 4 & 4 & 5 \\
\hline 2 & 4 & 0 & 4 & 4 & 5 & 4 \\
\hline 3 & 4 & 0 & 4 & 5 & 4 & 4 \\
\hline 4 & 4 & 0 & 5 & 4 & 4 & 4 \\
\hline 5 & 5 & 0 & 4 & 4 & 4 & 4 \\
\hline Average & 4.2 & 0 & 4.2 & 4.2 & 4.2 & 4.2 \\
\hline$\%$ Distribution within each class & $50 \%$ & $0 \%$ & $50 \%$ & $33.3 \%$ & $33.3 \%$ & $33.3 \%$ \\
\hline$\%$ Distribution overall & $20 \%$ & $0 \%$ & $20 \%$ & $20 \%$ & $20 \%$ & $20 \%$ \\
\hline Distribution per class & $\begin{array}{l}\text { A1,B1,C1 } \\
\text { A2,B2,C2 }\end{array}$ & $\begin{array}{l}\text { Total of class average } \\
8.4 \\
12.6\end{array}$ & $\begin{array}{l}\% \text { of Total per class } \\
40 \% \\
60 \%\end{array}$ & & & \\
\hline
\end{tabular}


Table 9. The Distribution of Tokens across Trials for P9

\begin{tabular}{|c|c|c|c|c|c|c|}
\hline Trials & Stimuli & & & & & \\
\hline Phase 4 & A1 & B1 & $\mathrm{C} 1$ & $\mathrm{~A} 2$ & B2 & $\mathrm{C} 2$ \\
\hline NO Function & ZID & YIM & FAP & VEK & RIX & KUD \\
\hline 1 & 3 & 3 & 4 & 4 & 3 & 4 \\
\hline 2 & 3 & 3 & 4 & 4 & 3 & 4 \\
\hline 3 & 3 & 3 & 4 & 4 & 3 & 4 \\
\hline 4 & 3 & 3 & 4 & 4 & 3 & 4 \\
\hline 5 & 3 & 3 & 4 & 4 & 3 & 4 \\
\hline Average & 3 & 3 & 4 & 4 & 3 & 4 \\
\hline$\%$ Distribution within each class & $30.0 \%$ & $30.0 \%$ & $40 \%$ & $36.4 \%$ & $27.3 \% \%$ & $36.4 \%$ \\
\hline$\%$ Distribution overall & $14.3 \%$ & $14.3 \%$ & $19.0 \%$ & $19.0 \%$ & $14.3 \%$ & $19.0 \%$ \\
\hline Distribution per class & $\begin{array}{l}\text { A1,B1,C1 } \\
\text { A2,B2,C2 }\end{array}$ & $\begin{array}{l}\text { Total of class average } \\
10 \\
11\end{array}$ & $\begin{array}{l}\% \text { of Total per class } \\
47.6 \% \\
52.4 \%\end{array}$ & & & \\
\hline \multicolumn{7}{|l|}{ Phase 6} \\
\hline 1 & 3 & 6 & 3 & 3 & 3 & 3 \\
\hline 2 & 3 & 6 & 3 & 3 & 3 & 3 \\
\hline 3 & 3 & 6 & 3 & 3 & 3 & 3 \\
\hline 4 & 3 & 6 & 3 & 3 & 3 & 3 \\
\hline 5 & 3 & 6 & 3 & 3 & 3 & 3 \\
\hline Average & 3 & 6 & 3 & 3 & 3 & 3 \\
\hline$\%$ Distribution within each class & $25 \%$ & $50 \%$ & $25 \%$ & $33.3 \%$ & $33.3 \%$ & $33.3 \%$ \\
\hline$\%$ Distribution overall & $14.3 \%$ & $28.6 \%$ & $14.3 \%$ & $14.3 \%$ & $14.3 \%$ & $14.3 \%$ \\
\hline Distribution per class & $\begin{array}{l}\text { A1,B1,C1 } \\
\text { A2,B2,C2 }\end{array}$ & $\begin{array}{l}\text { Total of class average } \\
12 \\
9\end{array}$ & $\begin{array}{l}\% \text { of Total per class } \\
57.2 \% \\
42.8 \%\end{array}$ & & & \\
\hline \multicolumn{7}{|l|}{ Phase 8} \\
\hline 1 & 4 & 1 & 4 & 4 & 4 & 4 \\
\hline 2 & 4 & 1 & 4 & 4 & 4 & 4 \\
\hline 3 & 4 & 1 & 4 & 4 & 4 & 4 \\
\hline 4 & 4 & 1 & 4 & 4 & 4 & 4 \\
\hline 5 & 4 & 1 & 4 & 4 & 4 & 4 \\
\hline Average & 4 & 1 & 4 & 4 & 4 & 4 \\
\hline$\%$ Distribution within each class & $44.4 \%$ & $11.1 \%$ & $44.4 \%$ & $33.3 \%$ & $33.3 \%$ & $33.3 \%$ \\
\hline$\%$ Distribution overall & $19.0 \%$ & $4.8 \%$ & $19.0 \%$ & $19.0 \%$ & $19.0 \%$ & $19.0 \%$ \\
\hline Distribution per class & $\begin{array}{l}\mathrm{A} 1, \mathrm{~B} 1, \mathrm{C} 1 \\
\mathrm{~A} 2, \mathrm{~B} 2, \mathrm{C} 2\end{array}$ & $\begin{array}{l}\text { Total of class average } \\
9 \\
12\end{array}$ & $\begin{array}{l}\% \text { of Total per class } \\
42.8 \% \\
57.2 \%\end{array}$ & & & \\
\hline
\end{tabular}


Table 10. The Distribution of Tokens across Trials for P10

\begin{tabular}{|c|c|c|c|c|c|c|}
\hline Trials & Stimuli & & & & & \\
\hline Phase 4 & A1 & B1 & $\mathrm{C} 1$ & $\mathrm{~A} 2$ & B2 & $\mathrm{C} 2$ \\
\hline NO Function & ZID & YIM & FAP & VEK & RIX & KUD \\
\hline 1 & 0 & 5 & 7 & 0 & 0 & 9 \\
\hline 2 & 0 & 5 & 7 & 0 & 0 & 9 \\
\hline 3 & 0 & 5 & 7 & 0 & 0 & 9 \\
\hline 4 & 0 & 5 & 7 & 0 & 0 & 9 \\
\hline 5 & 0 & 5 & 7 & 0 & 0 & 9 \\
\hline Average & 0 & 5 & 7 & 0 & 0 & 9 \\
\hline$\%$ Distribution within each class & $0 \%$ & $41.7 \%$ & $58.3 \%$ & $0 \%$ & $0 \%$ & $100 \%$ \\
\hline$\%$ Distribution overall & $0 \%$ & $23.8 \%$ & $33.3 \%$ & $0 \%$ & $0 \%$ & $42.9 \%$ \\
\hline Distribution per class & $\begin{array}{l}\text { A1,B1,C1 } \\
\text { A2,B2,C2 }\end{array}$ & $\begin{array}{l}\text { Total of class average } \\
12 \\
9\end{array}$ & $\begin{array}{l}\% \text { of Total per class } \\
57.1 \% \\
42.9 \%\end{array}$ & & & \\
\hline \multicolumn{7}{|l|}{ Phase 6} \\
\hline 1 & 0 & 21 & 0 & 0 & 0 & 0 \\
\hline 2 & 0 & 21 & 0 & 0 & 0 & 0 \\
\hline 3 & 0 & 21 & 0 & 0 & 0 & 0 \\
\hline 4 & 0 & 21 & 0 & 0 & 0 & 0 \\
\hline 5 & 0 & 21 & 0 & 0 & 0 & 0 \\
\hline Average & 0 & 21 & 0 & 0 & 0 & 0 \\
\hline$\%$ Distribution within each class & $0 \%$ & $100 \%$ & $0 \%$ & $0 \%$ & $0 \%$ & $0 \%$ \\
\hline$\%$ Distribution overall & $0 \%$ & $100 \%$ & $0 \%$ & $0 \%$ & $0 \%$ & $0 \%$ \\
\hline Distribution per class & $\begin{array}{l}\mathrm{A} 1, \mathrm{~B} 1, \mathrm{C} 1 \\
\mathrm{~A} 2, \mathrm{~B} 2, \mathrm{C} 2\end{array}$ & $\begin{array}{l}\text { Total of class average } \\
11 \\
10\end{array}$ & $\begin{array}{l}\% \text { of Total per class } \\
52.3 \% \\
47.6 \%\end{array}$ & & & \\
\hline \multicolumn{7}{|l|}{ Phase 8} \\
\hline 1 & 4 & 0 & 5 & 4 & 4 & 4 \\
\hline 2 & 4 & 0 & 5 & 4 & 4 & 4 \\
\hline 3 & 4 & 0 & 5 & 4 & 4 & 4 \\
\hline 4 & 4 & 0 & 5 & 4 & 4 & 4 \\
\hline 5 & 4 & 0 & 5 & 4 & 4 & 4 \\
\hline Average & 4 & 0 & 5 & 4 & 4 & 4 \\
\hline$\%$ Distribution within each class & $44.4 \%$ & $0 \%$ & $55.6 \%$ & $33.3 \%$ & $33.3 \%$ & $33.3 \%$ \\
\hline$\%$ Distribution overall & $19.0 \%$ & $0 \%$ & $23.8 \%$ & $19.0 \%$ & $19.0 \%$ & $19.0 \%$ \\
\hline Distribution per class & $\begin{array}{l}\mathrm{A} 1, \mathrm{~B} 1, \mathrm{C} 1 \\
\mathrm{~A} 2, \mathrm{~B} 2, \mathrm{C} 2\end{array}$ & $\begin{array}{l}\text { Total of class average } \\
9 \\
12\end{array}$ & $\begin{array}{l}\% \text { of Total per class } \\
42.8 \% \\
57.2 \%\end{array}$ & & & \\
\hline
\end{tabular}


Table 11. The Distribution of Tokens across Trials for P11

\begin{tabular}{|c|c|c|c|c|c|c|}
\hline Trials & Stimuli & & & & & \\
\hline Phase 4 & A1 & B1 & $\mathrm{C} 1$ & $\mathrm{~A} 2$ & B2 & $\mathrm{C} 2$ \\
\hline NO Function & ZID & YIM & FAP & VEK & RIX & KUD \\
\hline 1 & 4 & 4 & 4 & 3 & 3 & 3 \\
\hline 2 & 4 & 4 & 4 & 3 & 3 & 3 \\
\hline 3 & 4 & 4 & 4 & 3 & 3 & 3 \\
\hline 4 & 3 & 3 & 3 & 4 & 4 & 4 \\
\hline 5 & 3 & 3 & 3 & 4 & 4 & 4 \\
\hline Average & 3.6 & 3.6 & 3.6 & 3.4 & 3.4 & 3.4 \\
\hline$\%$ Distribution within each class & $33.3 \%$ & $33.3 \%$ & $33.3 \%$ & $33.3 \%$ & $33.3 \%$ & $33.3 \%$ \\
\hline$\%$ Distribution overall & $17.1 \%$ & $17.1 \%$ & $17.1 \%$ & $16.2 \%$ & $16.2 \%$ & $16.2 \%$ \\
\hline Distribution per class & $\begin{array}{l}\mathrm{A} 1, \mathrm{~B} 1, \mathrm{C} 1 \\
\mathrm{~A} 2, \mathrm{~B} 2, \mathrm{C} 2\end{array}$ & $\begin{array}{l}\text { Total of class average } \\
10.8 \\
10.2\end{array}$ & $\begin{array}{l}\% \text { of Total per class } \\
51.3 \% \\
48.7 \%\end{array}$ & & & \\
\hline \multicolumn{7}{|l|}{ Phase 6} \\
\hline 1 & 0 & 21 & 0 & 0 & 0 & 0 \\
\hline 2 & 0 & 21 & 0 & 0 & 0 & 0 \\
\hline 3 & 0 & 21 & 0 & 0 & 0 & 0 \\
\hline 4 & 0 & 21 & 0 & 0 & 0 & 0 \\
\hline 5 & 0 & 21 & 0 & 0 & 0 & 0 \\
\hline Average & 0 & 21 & 0 & 0 & 0 & 0 \\
\hline$\%$ Distribution within each class & $0 \%$ & $100 \%$ & $0 \%$ & $0 \%$ & $0 \%$ & $0 \%$ \\
\hline$\%$ Distribution overall & $0 \%$ & $100 \%$ & $0 \%$ & $0 \%$ & $0 \%$ & $0 \%$ \\
\hline Distribution per class & $\begin{array}{l}\mathrm{A} 1, \mathrm{~B} 1, \mathrm{C} 1 \\
\mathrm{~A} 2, \mathrm{~B} 2, \mathrm{C} 2\end{array}$ & $\begin{array}{l}\text { Total of class average } \\
21 \\
0\end{array}$ & $\begin{array}{l}\% \text { of Total per class } \\
100 \% \\
0 \%\end{array}$ & & & \\
\hline \multicolumn{7}{|l|}{ Phase 8} \\
\hline 1 & 5 & 0 & 4 & 4 & 4 & 4 \\
\hline 2 & 4 & 0 & 5 & 4 & 4 & 4 \\
\hline 3 & 4 & 0 & 4 & 5 & 4 & 4 \\
\hline 4 & 4 & 0 & 4 & 4 & 5 & 4 \\
\hline 5 & 4 & 0 & 4 & 4 & 4 & 5 \\
\hline Average & 4.2 & 0 & 4.2 & 4.2 & 4.2 & 4.2 \\
\hline$\%$ Distribution within each class & $50 \%$ & $0 \%$ & $50 \%$ & $33.3 \%$ & $33.3 \%$ & $33.3 \%$ \\
\hline$\%$ Distribution overall & $20 \%$ & $0 \%$ & $20 \%$ & $20 \%$ & $20 \%$ & $20 \%$ \\
\hline Distribution per class & $\begin{array}{l}\mathrm{A} 1, \mathrm{~B} 1, \mathrm{C} 1 \\
\mathrm{~A} 2, \mathrm{~B} 2, \mathrm{C} 2\end{array}$ & $\begin{array}{l}\text { Total of class average } \\
8.4 \\
12.6\end{array}$ & $\begin{array}{l}\% \text { of Total per class } \\
40 \% \\
60 \%\end{array}$ & & & \\
\hline
\end{tabular}


Table 12. The Distribution of Tokens across Trials for P12

\begin{tabular}{|c|c|c|c|c|c|c|}
\hline Trials & Stimuli & & & & & \\
\hline Phase 4 & A1 & B1 & $\mathrm{C} 1$ & $\mathrm{~A} 2$ & B2 & $\mathrm{C} 2$ \\
\hline NO Function & ZID & YIM & FAP & VEK & RIX & KUD \\
\hline 1 & 3 & 4 & 6 & 4 & 3 & 1 \\
\hline 2 & 3 & 4 & 4 & 4 & 3 & 3 \\
\hline 3 & 3 & 4 & 4 & 4 & 3 & 3 \\
\hline 4 & 3 & 4 & 4 & 4 & 3 & 3 \\
\hline 5 & 3 & 4 & 4 & 4 & 3 & 3 \\
\hline Average & 3 & 4 & 4.4 & 4 & 3 & 2.6 \\
\hline$\%$ Distribution within each class & $26.3 \%$ & $35.1 \%$ & $38.6 \%$ & $41.7 \%$ & $31.3 \%$ & $27.1 \%$ \\
\hline$\%$ Distribution overall & $14.3 \%$ & $19.0 \%$ & $21.0 \%$ & $19.0 \%$ & $14.3 \%$ & $12.4 \%$ \\
\hline Distribution per class & $\begin{array}{l}\text { A1,B1,C1 } \\
\text { A2,B2,C2 }\end{array}$ & $\begin{array}{l}\text { Total of class average } \\
11.4 \\
9.6\end{array}$ & $\begin{array}{l}\% \text { of Total per class } \\
54.3 \% \\
45.7 \%\end{array}$ & & & \\
\hline \multicolumn{7}{|l|}{ Phase 6} \\
\hline 1 & 0 & 21 & 0 & 0 & 0 & 0 \\
\hline 2 & 0 & 21 & 0 & 0 & 0 & 0 \\
\hline 3 & 0 & 21 & 0 & 0 & 0 & 0 \\
\hline 4 & 4 & 13 & 4 & 0 & 0 & 0 \\
\hline 5 & 5 & 11 & 5 & 0 & 0 & 0 \\
\hline Average & 1.8 & 17.4 & 1.8 & 0 & 0 & 0 \\
\hline$\%$ Distribution within each class & $8.6 \%$ & $82.9 \%$ & $8.6 \%$ & $0 \%$ & $0 \%$ & $0 \%$ \\
\hline$\%$ Distribution overall & $8.6 \%$ & $82.9 \%$ & $8.6 \%$ & $0 \%$ & $0 \%$ & $0 \%$ \\
\hline Distribution per class & $\begin{array}{l}\mathrm{A} 1, \mathrm{~B} 1, \mathrm{C} 1 \\
\mathrm{~A} 2, \mathrm{~B} 2, \mathrm{C} 2\end{array}$ & $\begin{array}{l}\text { Total of class average } \\
21 \\
0\end{array}$ & $\begin{array}{l}\% \text { of Total per class } \\
100 \% \\
0 \%\end{array}$ & & & \\
\hline \multicolumn{7}{|l|}{ Phase 8} \\
\hline 1 & 4 & 0 & 3 & 4 & 5 & 5 \\
\hline 2 & 3 & 0 & 3 & 5 & 6 & 4 \\
\hline 3 & 4 & 0 & 4 & 2 & 8 & 3 \\
\hline 4 & 2 & 0 & 2 & 5 & 7 & 5 \\
\hline 5 & 0 & 0 & 0 & 6 & 8 & 7 \\
\hline Average & 2.6 & 0 & 2.4 & 4.4 & 6.8 & 4.8 \\
\hline$\%$ Distribution within each class & $52 \%$ & $0 \%$ & $48 \%$ & 27.5 & 42.5 & $30 \%$ \\
\hline$\%$ Distribution overall & $12.4 \%$ & $0 \%$ & $11.4 \%$ & $21 \%$ & $32.4 \%$ & $22.9 \%$ \\
\hline Distribution per class & $\begin{array}{l}\mathrm{A} 1, \mathrm{~B} 1, \mathrm{C} 1 \\
\mathrm{~A} 2, \mathrm{~B} 2, \mathrm{C} 2\end{array}$ & $\begin{array}{l}\text { Total of class average } \\
5 \\
16\end{array}$ & $\begin{array}{l}\% \text { of Total per class } \\
23.8 \% \\
76.2 \%\end{array}$ & & & \\
\hline
\end{tabular}


Table 13. The Distribution of Tokens across Trials for P13

\begin{tabular}{|c|c|c|c|c|c|c|}
\hline Trials & Stimuli & & & & & \\
\hline Phase 4 & A1 & B1 & $\mathrm{C} 1$ & $\mathrm{~A} 2$ & $\mathrm{~B} 2$ & $\mathrm{C} 2$ \\
\hline NO Function & ZID & YIM & FAP & VEK & RIX & KUD \\
\hline 1 & 3 & 3 & 3 & 4 & 4 & 4 \\
\hline 2 & 4 & 4 & 4 & 3 & 3 & 3 \\
\hline 3 & 3 & 3 & 3 & 4 & 4 & 4 \\
\hline 4 & 4 & 4 & 4 & 3 & 3 & 3 \\
\hline 5 & 3 & 3 & 3 & 4 & 4 & 4 \\
\hline Average & 3.4 & 3.4 & 3.4 & 3.6 & 3.6 & 3.6 \\
\hline$\%$ Distribution within each class & $33.3 \%$ & $33.3 \%$ & $33.3 \%$ & $33.3 \%$ & $33.3 \%$ & $33.3 \%$ \\
\hline$\%$ Distribution overall & $16.2 \%$ & $16.2 \%$ & $16.2 \%$ & $17.1 \%$ & $17.1 \%$ & $17.1 \%$ \\
\hline Distribution per class & $\begin{array}{l}\text { A1,B1,C1 } \\
\text { A2,B2,C2 }\end{array}$ & $\begin{array}{l}\text { Total of class average } \\
10.2 \\
10.8\end{array}$ & $\begin{array}{l}\% \text { of Total per class } \\
48.6 \% \\
51.4 \%\end{array}$ & & & \\
\hline $\begin{array}{l}\text { Phase } 6 \\
\text { YIM Good }\end{array}$ & \multicolumn{5}{|c|}{ Phase 6} & \\
\hline 1 & 1 & 16 & 1 & 1 & 1 & 1 \\
\hline 2 & 1 & 16 & 1 & 1 & 1 & 1 \\
\hline 3 & 1 & 16 & 1 & 1 & 1 & 1 \\
\hline 4 & 1 & 16 & 1 & 1 & 1 & 1 \\
\hline 5 & 1 & 16 & 1 & 1 & 1 & 1 \\
\hline Average & 1 & 16 & 1 & 1 & 1 & 1 \\
\hline$\%$ Distribution within each class & $5.6 \%$ & $88.9 \%$ & $5.6 \%$ & $33.3 \%$ & $33.3 \%$ & $33.3 \%$ \\
\hline$\%$ Distribution overall & $4.8 \%$ & $76.2 \%$ & $4.8 \%$ & $4.8 \%$ & $4.8 \%$ & $4.8 \%$ \\
\hline Distribution per class & $\begin{array}{l}\text { A1,B1,C1 } \\
\text { A2,B2,C2 }\end{array}$ & $\begin{array}{l}\text { Total of class average } \\
18 \\
3\end{array}$ & $\begin{array}{l}\% \text { of Total per class } \\
85.8 \% \\
14.2 \%\end{array}$ & & & \\
\hline \multicolumn{7}{|l|}{ Phase 8} \\
\hline 1 & 4 & 1 & 4 & 4 & 4 & 4 \\
\hline 2 & 4 & 1 & 4 & 4 & 4 & 4 \\
\hline 3 & 4 & 1 & 4 & 4 & 4 & 4 \\
\hline 4 & 4 & 1 & 4 & 4 & 4 & 4 \\
\hline 5 & 4 & 1 & 4 & 4 & 4 & 4 \\
\hline Average & 4 & 1 & 4 & 4 & 4 & 4 \\
\hline$\%$ Distribution within each class & $44.4 \%$ & $11.1 \%$ & $44.4 \%$ & $33.3 \%$ & $33.3 \%$ & $33.3 \%$ \\
\hline$\%$ Distribution overall & $19.0 \%$ & $4.8 \%$ & $19.0 \%$ & $19.0 \%$ & $19.0 \%$ & $19.0 \%$ \\
\hline Distribution per class & $\begin{array}{l}\text { A1,B1,C1 } \\
\text { A2,B2,C2 }\end{array}$ & $\begin{array}{l}\text { Total of class average } \\
9 \\
12\end{array}$ & $\begin{array}{l}\% \text { of Total per class } \\
42.8 \% \\
57.2 \%\end{array}$ & & & \\
\hline
\end{tabular}


Open Access This article is licensed under a Creative Commons Attribution 4.0 International License, which permits use, sharing, adaptation, distribution and reproduction in any medium or format, as long as you give appropriate credit to the original author(s) and the source, provide a link to the Creative Commons licence, and indicate if changes were made. The images or other third party material in this article are included in the article's Creative Commons licence, unless indicated otherwise in a credit line to the material. If material is not included in the article's Creative Commons licence and your intended use is not permitted by statutory regulation or exceeds the permitted use, you will need to obtain permission directly from the copyright holder. To view a copy of this licence, visit http://creativecommons.org/licenses/by/4.0/.

\section{References}

Ajzen, I., \& Fishbein, M. (2005). The influence of attitudes on behavior. In D. Albarracín, B. T. Johnson, \& M. P. Zanna (Eds.), The handbook of attitudes (pp. 173-221). Mahwah, NJ: Lawrence Erlbaum Associates.

Arntzen, E., Nartey, R. K., \& Fields, L. (2014). Identity and delay functions of meaningful stimuli: Enhanced equivalence class formation. The Psychological Record, 64, 349-360.

Barnes, D., Browne, M., Smeets, P. M., \& Roche, B. (1995). A transfer of functions and a conditional transfer of functions through equivalence relations in three to six-year-old children. The Psychological Record, 45, 405-430.

Barnes, D., \& Keenan, M. (1993). A transfer of functions through derived arbitrary and non-arbitrary stimulus relations. Journal of the Experimental Analysis of Behavior, 59, 61-81.

Barnes, D., Lawlor, H., Smeets, P. M., \& Roche, B. (1996). Stimulus equivalence and academic self-concept in mildly mentally handicapped and non-mentally handicapped children. The Psychological Record, 46, 87-107.

Barnes-Holmes, D., Barnes-Holmes, Y., Smeets, P. M., Cullinan, V., \& Leader, G. (2004). Relational frame theory and stimulus equivalence: Conceptual and procedural issues. International Journal of Psychology \& Psychological Therapy, 4, 181-214.

Barros, R. S., Lionello-DeNolf, K. M., Dube, W. V., \& McIlvane, W. J. (2006). Equivalence class formation via identity matching to sample and simple discrimination with class-specific consequences. Revista Brasileira de Análise do Comportamento, 2, 79-92.

Bolton, G. E., Katok, E., \& Ockenfels, A. (2004). How effective are online reputation mechanisms? An experimental study. Management Science, 50(11), 1587-1602.

Bones, R., Keenan, M., Askin, D., Adams, L., Taylor, D., \& Nicholas, O. (2001). The effects of response topography on functional equivalence class formation. The Psychological Record, 51, 89-110.

Bortoloti, R., Rodrigues, N. C., Cortez, M. D., Pimentel, N., \& de Rose, J. (2013). Overtraining increases the strength of equivalence relations. Psychology \& Neuroscience, 6(3), 357-364. https://doi.org/10. 3922/j.psns.2013.3.13.

Bush, K. M., Sidman, M., \& de Rose, T. (1989). Contextual control of emergent equivalence relations. Journal of the Experimental Analysis of Behavior, 51, 29-45.

Cadsby, C. B., Servátka, M., \& Song, F. (2010). Experimental Economics, 13(3), 299-308.

Cairns, E. (1984). Social identity in Northern Ireland. Human Relations, $37,1095-1102$.

Catania, A. C. (1992). Learning. Englewood Cliffs, NJ: Prentice Hall.

Dale, D. J., Morgan, J., \& Rosenthal, R. W. (2002). Coordination through reputations: A laboratory experiment. Games \& Economic Behavior, 38, 52-88.
Dixon, M. R., Rehfeldt, R. A., Zlomke, K. R., \& Robinson, A. (2006). Exploring the development and dismantling of equivalence classes involving terrorist stimuli. The Psychological Record, 56, 83-103.

Dougher, M. J., Augustson, E. M., Markham, M. R., Greenway, D. E., \& Wulfert, E. (1994). The transfer of respondent eliciting and extinction functions through stimulus equivalence classes. Journal of the Experimental Analysis of Behavior, 62, 331-351.

Dube, W. V., \& McIlvane, W. J. (1995). Stimulus-reinforcer relations and emergent matching to sample. The Psychological Record, 45, 591612.

Dube, W. V., McIlvane, W. J., Mackay, H. A., \& Stoddard, L. T. (1987). Stimulus class membership via stimulus-reinforcer relations. Journal of the Experimental Analysis of Behavior, 47, 159-175.

Dymond, S., \& Barnes, D. (1996). A transformation of selfdiscrimination response functions in accordance with the arbitrarily applicable relations of sameness and opposition. The Psychological Record, 46(2), 271-300.

Dymond, S., \& Rehfeldt, R. A. (2000). Understanding complex behavior: The transformation of stimulus functions. The Behavior Analyst, 23, 239-254.

Ellemers, N., Kortekaas, P., \& Ouwerkerk, J. W. (1999). Selfcategorisation, commitment to the group and group self-esteem as related but distinct aspects of social identity. European Journal of Social Psychology, 29, 371-389.

Fields, L., Arntzen, E., Nartey, R. N., \& Eilifsen, C. (2012). Effects of a meaningful, a discriminative, and a meaningless stimulus on equivalence class formation. Journal of the Experimental Analysis of Behavior, 97, 163-181.

Gaertner, S. L., Dovidio, J. F., Anastasio, P. A., Bachman, B. A., \& Rust, M. C. (1993). The Common Ingroup Identity Model: Recategorization and the reduction of intergroup bias. European Review of Social Psychology, 4, 1-26.

Gatch, M. B., \& Osborne, J. G. (1989). Transfer of contextual stimulus function via equivalence class development. Journal of the Experimental Analysis of Behavior, 51, 369-378.

Giles, H., Reid, S. A., \& Harwood, J. (Eds.). (2010). The dynamics of intergroup communication. New York, NY: Peter Lang.

Greenway, D. E., Dougher, M. J., \& Wulfert, E. (1996). The transfer of conditioned reinforcement and punishment functions through stimulus equivalence classes. The Psychological Record, 46, 131-144.

Grey, I., \& Barnes, D. (1996). Stimulus equivalence and attitudes. The Psychological Record, 46, 243-270.

Guala, F., \& Mittone, L. (2010). Paradigmatic experiments: The Dictator Game. Journal of Behavioral \& Experimental Economics, 39(5), 578-584.

Hayes, S. C. (Ed.). (1989). Rule-governed behavior: Cognition, contingencies, and instructional control. New York, NY: Plenum Press.

Hayes, S. C., Brownstein, A. J., Zettle, R. D., Rosenfard, I., \& Kom, Z. (1986). Ruel-governed behavior and sensitivity to changing consequences of responding. Journal of the Experimental Analysis of Behavior, 45(3), 237-256.

Hayes, S. C., Kohlenberg, B. S., \& Hayes, L. J. (1991). The transfer of specific and general consequential functions through simple and conditional equivalence relations. Journal of the Experimental Analysis of Behavior, 56(1), 119-137.

Hewstone, M., Stroebe, W., \& Jonas, K. (2012). An introduction to social psychology. Sussex, UK: British Psychological Society/John Wiley \& Sons.

Hogg, M., \& Vaughan, G. (2005). Social psychology (4th ed.). London, UK: Prentice Hall.

Hogg, M., \& Vaughan, G. (2010). Essentials of social psychology. Essex, UK: Pearson Education.

Hughes, S., Barnes-Holmes, D., \& De Houwer, J. (2011). The dominance of associative theorising in implicit attitude research: Propositional and behavioral alternatives. The Psychological Record, 61, 465498. 
Keenan, M. (1999). Periodic response-reinforcer contiguity: Temporal control but not as we know it. The Psychological Record, 49, 273-297.

Killeen, P. R. (2014). A theory of behavioral contrast. Journal of the Experimental Analysis of Behavior, 102, 363-390. https://doi.org/ 10.1002/jeab.107.

Kohlenberg, B. S., Hayes, S. C., \& Hayes, L. J. (1991). The transfer of contextual control over equivalence classes through equivalence classes: A possible model of social stereotyping. Journal of the Experimental Analysis of Behavior, 56, 505-518.

Kruglanski, A. W., \& Stroebe, W. (Eds.). (2012). Handbook of the history of social psychology. New York, NY: Psychology Press.

Leslie, J. C., Tierney, K. J., Robinson, C. P., Keenan, M., Watt, A. A., \& Barnes, D. (1993). Differences between clinically anxious and nonanxious subjects in a stimulus equivalence training task involving threatening words. The Psychological Record, 43, 153-161.

Lionello-DeNolf, K. M., Dube, W. V., \& McIlvane, W. J. (2006). Equivalence class formation via identity matching to sample and simple discrimination via simple discrimination with class-specific consequences. Revista Brasileira de Analyise do Comportamento, 2 , $125-133$

Lowe, C. F., Harzem, P., \& Hughe, S. (1978). Determinants of operant behavior in humans: Some differences from animals. Quarterly Journal of Experimental Psychology, 30, 373-386.

McGlinchey, A., \& Keenan, M. (1997). Stimulus equivalence and social categorization in Northern Ireland. Behavior \& Social Issues, 7, $113-128$.

McGlinchey, A., Keenan, M., \& Dillenburger, K. (2000). Outline for the development of a screening procedure for children who have been sexually abused. Research on Social Work Practice, 10, 722-747.

McGuigan, S., \& Keenan, M. (2002). Rule following in functional equivalence classes. European Journal of Behavior Analysis, (1), 21-29.

McVeigh, B., \& Keenan, M. (2009). Multiple functions in equivalence classes. The Psychological Record, 59, 93-117.

Merwin, R. M., \& Wilson, K. G. (2005). Preliminary findings on the effects of self-referring and evaluative stimuli on stimulus equivalence class formation. The Psychological Record, 55, 561-575.

Moxon, P. D., Keenan, M., \& Hine, L. (1993). Gender-role stereotyping and stimulus equivalence. The Psychological Record, 43, 381-394.

O'Reilly, A., Roche, B., Ruiz, M., Tyndall, T., \& Gavin, A. (2012). The Function Acquisition Speed Test (FAST): A behavior analytic implicit test for assessing stimulus relations. The Psychological Record, 62, 507-528.

O'Hora, D., Roche, B., Barnes-Holmes, D., \& Smeets, P. M. (2002). Response latencies to multiple derived stimulus relations: Testing two predictions of relational frame theory. The Psychological Record, 52, 51-76.

Pilgrim, C. (2004). How far can equivalence take us? An emergent story. Conference presented at the $2^{\text {nd }}$ Association for Behavior Analysis International Meeting, Campinas, SP, Brazil.

Plaud, J. J. (1995). The formation of stimulus equivalences: Fear-relevant versus fear-irrelevant stimulus classes. The Psychological Record, $45,207-222$.

Randell, T., \& Remington, B. (2006). Equivalence relations, contextual control, and naming. Journal of the Experimental Analysis of Behavior, 86, 337-354.

Roche, B., \& Barnes, D. (1996). Arbitrarily applicable relational responding and sexual categorization: A critical test of the difference relation. The Psychological Record, 46, 451-475.
Roche, B., Barnes-Holmes, Y., Barnes-Holmes, D., Stewart, I., \& O'Hora, D. (2002). Relational frame theory: A new paradigm for the analysis of social behavior. The Behavior Analyst, 25(1), 75-91.

Roche, B., O'Reilly, A., Gavin, A., Ruiz, M., \& Arancibia, G. (2012). Using behavior-analytic implicit tests to assess sexual interests among normal and sex-offender populations. Socioaffective Neuroscience \& Psychology, 2, 17335.

Roche, B., Ruiz, R., O'Riordan, M., \& Hand, K. (2005). A relational frame approach to the psychological assessment of sex offenders. In M. Taylor \& E. Quayle (Eds.), New developments in child pornography and the internet (pp. 109-125). Russell House: Dorset, UK.

Rousu, M., \& Baublitz, S. J. (2011). Does perceived unfairness affect charitable giving? Evidence from the dictator game. Journal of Behavioral \& Experimental Economics, 40(4), 364-367.

Schauss, S. L., Chase, P. N., \& Hawkins, R. P. (1997). Environmentbehavior relations, behavior therapy and the process of persuasion and attitude change. Journal of Behavior Therapy \& Experimental Psychiatry, 28, 31-40.

Schenk, J. J. (1994). Emergent relations of equivalence generated by outcome-specific consequences in conditional discrimination. The Psychological Record, 44, 537-558.

Schlinger, H. D. (2020). Comments on behavioral observations podcast. Operants, 1, 17-20.

Schmidt, D., Shupp, R., Walker, J. M., \& Ostrom, E. (2003). Playing safe in coordination games: The roles of risk dominance, payoff dominance, and history of play. Games \& Economic Behavior, 42, $281-$ 299.

Servátka, M. (2010). Does generosity generate generosity? An experimental study of reputation effects in a dictator game. The Journal of Socio-Economics, 39(1), 11-17.

Stahlberg, D., \& Frey, D. (1988). Attitudes 1: Structure, measurement and functions. In M. Hewstone, W. Stroebe, J. P. Codol, \& G. M. Stephenson (Eds.), Introduction to social psychology. Oxford, UK: Blackwell.

Tammi, T. (2013). Dictator game giving and norms of redistribution: Does giving in the dictator game parallel with the supporting of income redistribution in the field? Journal of Behavioral \& Experimental Economics, 43(c), 44-48.

Tonneau, F. (2001). Equivalence relations: A reply. European Journal of Behavior Analysis, 2, 99-128.

Watt, A., Keenan, M., Barnes, D., \& Cairns, E. (1991). Social categorization and stimulus equivalence. The Psychological Record, 41, 3350.

Whelan, R., \& Barnes-Holmes, D. (2004). The transformation of consequential functions in accordance with the relational frames of same and opposite. Journal of the Experimental Analysis of Behavior, 82, 177-195.

Whelan, R., Barnes-Holmes, D., \& Dymond, S. (2006). The transformation of consequential functions in accordance with the relational frames of more-than and less-than. Journal of the Experimental Analysis of Behavior, 86, 317-335.

Publisher's Note Springer Nature remains neutral with regard to jurisdictional claims in published maps and institutional affiliations. 